

\section{Voor de uitgave van de resultaten der Siboga-Expeditie hebben bijdragen beschikbaar gesteld:}

De Maatschappij ter bevordering van het Natuurkundig Onderzoek der Nederlandsche Kolonièn.

Het Ministerie van Koloniën.

Het Ministerie van Binnenlandsche Zaken.

Het Koninklijk Zoologisch Gehootschap "Natura Artis Magistra" te Amsterdam.

De sOostersche Handel en Reederij" te Amsterdam.

De Heer B. H DE WAAL Oud-Consul-Generaal der Nederlanden te Kaapstad.

M. B. te Amsterdam. 


SIBOGA-EXPEDITIE. 


\section{Siboga-Expeditie}

\section{UITKOMSTEN}

OP

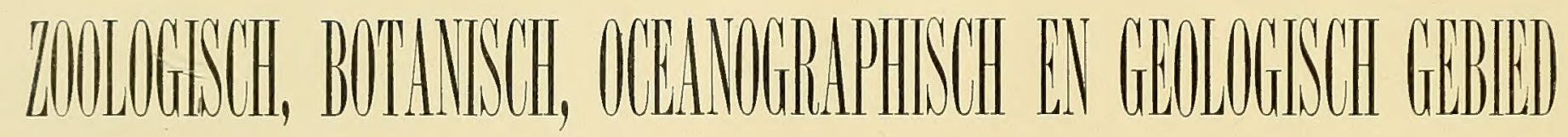

VERZAMELD IN

\section{NEDERLANDSCH OOST-INDIË I899-I900}

A AN BOORD H. M. SIBOGA ONDER COMMANDO VAN

Luitenant ter zee $1^{\mathrm{e}} \mathrm{kl}$. G. F. TYDEMAN

UITGEGEVEN DOOR

\section{Dr. MAX WEBER}

Prof. in Amsterdam, Leider der Expeditie

\section{(met medewerking van de Maatschappij ter bevordering van het Natuurkundig onderzoek der Nederlandsche Koloniën)}

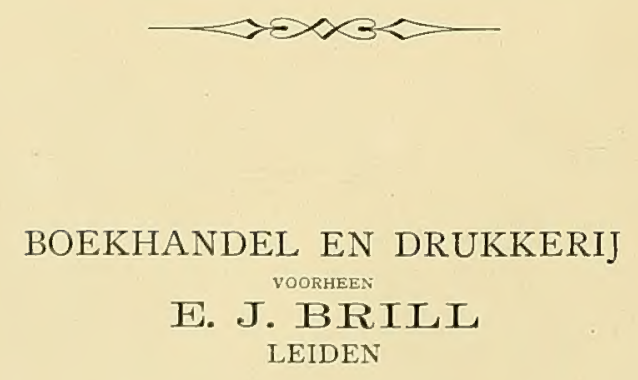




\section{Siboga-Expeditie} $\mathrm{XXX}$

DIE

\section{OSTRACODEN DER SIBOGA-EXPEDITION}

$\mathrm{VON}$

G. W. MÜLLER

Mit neun Tafeln
17.

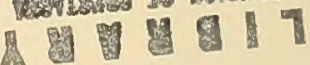

IAVERTEBRATE ZOOLOGY

Crustaces 



\section{INHALTSÜBERSICHT.}

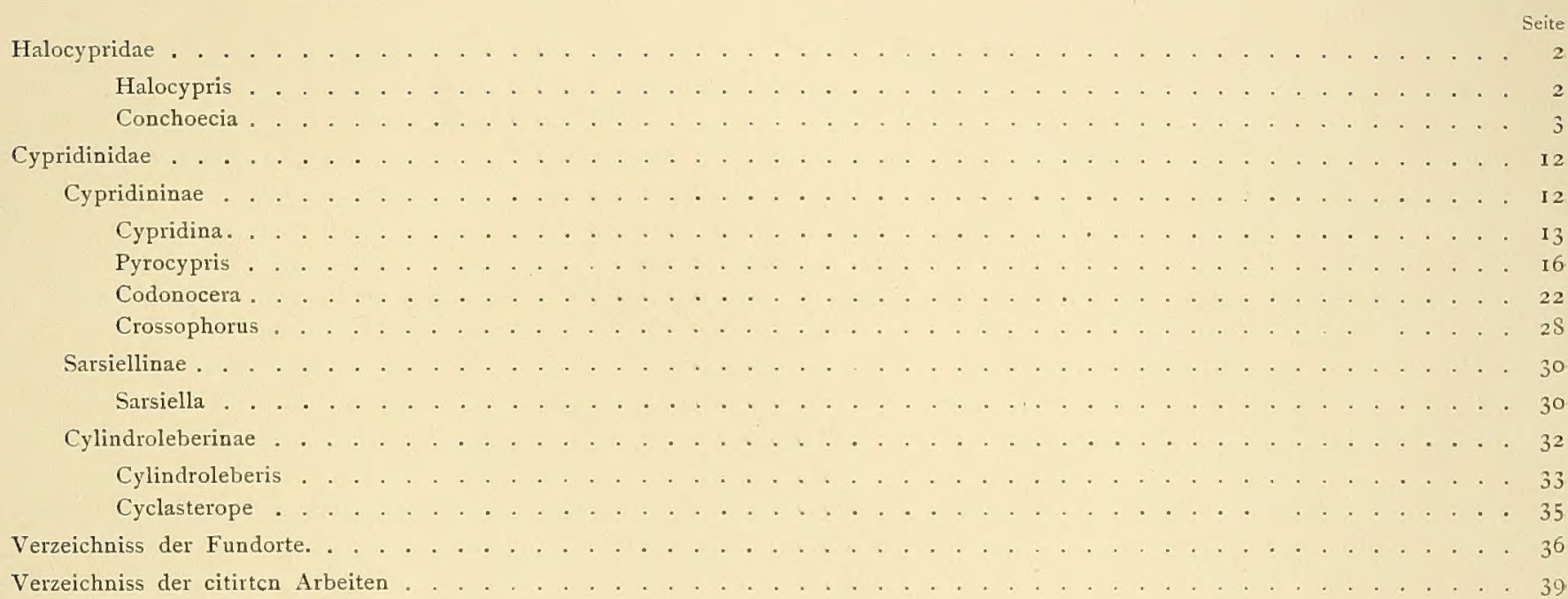





\title{
DIE OSTRACODEN DER SIBOGA-EXPEDITION
}

\author{
TON
}

\author{
G. W. MÜLLER,
}

Greifswald.

Mit neun Tafeln.

Die Ostracodensammlung der Siboga umfasst 56 Arten, von denen 3 I der Familie der Halocypriden, 25 der der Cypridiniden angehörten. Die Halocypriden sind fast sammtlich identisch mit Formen, die von der Valdivia im atlantischen oder indischen Ocean gesammelt, in den Ergebnissen dieser Expedition beschrieben sind, nur 2 Arten sind neu.

Um so reicher ist die Ausbeute an neuen Arten bei den Cypridiniden - von 25 Arten ${ }^{1}$ ) waren 15 neu - bei den bekannten Arten gestattete das Material vielfach eine Vervollständigung der Darstellung. Die meisten Arten von Cypridiniden waren durch zahlreiche Individuen vertreten, was fuir die systematische Untersuchung von grosser Bedeutung.

Soweit mir bekannt, hat noch keine wissenschaftliche Expedition ein so reiches Material von Cypridiniden, eine so grosse Zahl von Arten nach Haus gebracht. Wie das zu erklären, ob aus der besonderen Gunst des Terrains, dem ungewöhnlichen Reichthum des untersuchten Meeres an Cypridiniden, oder aus den angewandten Methoden des Sammelns, auf diese Frage komme ich am Schluss der Zusammenstellung der Fundorte und Fänge noch einmal zurick; vermuthlich aus dem Zusammenwirken beider Factoren.

I) Einschliesslich einer unbestimmbaren, aber beschriebenen Larve von Sarsiella. 


\section{HALOCYPRIDAE.}

Diagnose vergl. G. W. Müller, I906, S. 30.

\section{Halocypris Dana.}

Diagnose vergl. G. W. Müller, I906, S. 46.

I. Halocypris globosa (Claus).

1874. Halocypria globosa Claus, I874, S. 7, Taf. 3, fig. 36, 39.

1906. Halocypris globosa G. W. Müller, 1906, S. 47, Taf. 8 (4), fig. I3-I6, I8, I9; Taf. 35 (3I), fig. I.

Stat. 203. - 2 q.

Verbreitung: Atlantik, Indik.

2. Halocypris inflata Dana.

1852. Halocypris inflata und brevirostris Dana, I852, S. I 301, Taf. 9I, fig. 8; S. I 303, Taf. 91 , fig. 9.

1874. Halocypris concha Claus, 1874, S. 7, Taf. 2, fig. 20-25; Taf. 3, fig. 26-35.

I890, 9I. Halocypris pelagica Claus, I890, S. 25, I89I, S. 78, Taf. 21, fig. I-II.

I890. Halocypris distincta Claus, I 890, S. 25.

1891. Halocypris dubia G. W. Müller, I89I, S. 269, Taf. 28, fig. I9, 23, 24, 30, 35.

1906. Halocypris inflata G. W. Müller, 1906, S. 50, Taf. 7 (3), fig. I9-28.

Stat. 243. - 7 Indiv.

Verbreitung: Atlantik, Indik, Pacifik.

3. Halocypris cornuta var. typica G. W. Müller.

1906. Halocypris comuta var. typica G. W. Müller, I906, S. 48, Taf. 8, fig. I-3, 5-7.

Stat. 14I. - 3 juv.

Stat. 143. - I 요 I $0^{7}$.

Stat. 185. - 2 , 1 , $0^{7}$.

Stat. 230. -3 ㅇ.

Stat. 243. - I Q.

Nach den oben citirten Beschreibung soll sich die var. dispar lediglich südlich vom $28^{\circ} \mathrm{S}$.Br. finden, weiter nördlich nur die var. typica vorkommen, eine Anschauung, welche durch die Funde der Siboga bestätigt wird.

Verbreitung: Atlantik, Indik. 


\section{Conchoecia Dana.}

Diagnose vergl. G. W. MÜLter, I906, S. 5 I.

I. Conchoecia spinifera (Claus).

I890, 91. Paraconchoecia spinifera Claus, I890, S. I4, I89I, S. 64, Taf. Io.

1906. Conchoecia spinifera G. W. Müller, I906, S. 56, Taf. 9 (5) fig. I-IO, I4, I5.

Stat. I4I. -3 .

Stat. $276 .-1$.

Verbreitung: Atlantik, Indik.

\section{Conchoecia oblonga (Claus).}

I890, 91. Paraconchoecia oblonga Claus, I890, S. I3, I891, S. 63, Taf. 8, fig. I0, II; Taf. 9. Non 1894. Paraconchoecia oblonga Claus, I894, S. 3, Taf. 3, fig. 21-23.

Non 189I. Conchoecia oblonga G. W. Müller, I89I, S. 273, Taf. 28, fig. 26, 3I, 32, 36, 37. 1906. Conchoecia oblonga G. W. Müller, 1906, S. 58, Taf. 9 (5) fig. I I-I3, I6-25.

I891. Conchoecia variabilis (pr. prt.), G. W. Müller, I89I, S. 273, Taf. 28, fig. 38.

Stat. $243 .-6$.

Stat. $276 .-2$.

Verbreitung: Atlantik, Indik.

3. Conchoecia echinata G. W. Müller.

1906. Conchoecia echinata G. W. Müller, 1906, S. 6I, Taf. Io (6), fig. 14-24. I906. Conchoecia notocera Vavra, I906, S. 58, Taf. 6, fig. I14-I20.

Stat. $243 .-20^{7}$.

Stat. $276 .-$ I 9 , I $\sigma^{7}$.

Verbreitung: Atlantik, Indik.

4. Conchoecia caudata G. W. Miuller.

I891. Conchoecia caudata G. W. Müller, I89I, S. 276, Taf. 29, fig. 45, 49. I906. Conchoecia caudata G. W. Müller, I906, S. 65, Taf. I2 (8), fig. I-9.

Stat. I I 2. - I Indiv.

Stat. 14I. - 6 Indiv.

Stat. I43. - I Indiv.

Stat. $185 .-5$ Indiv.

Stat. 203. - 3 Indiv.

Stat. 230. - I Indiv.

Stat. 243. - 2 Indiv.

Stat. $276 .-6$ Indiv.

Verbreitung: Atlantik, Indik, Pacifik. 
5. Conchoecia elegans G. O. Sars.

1865. Conchoecia elegans G. O. Sars, 1865, S. I17.

1906. Conchoecia elegans G. W. Müller, I906, S. 69, Taf. I3 (9), fig. I0, I I, 19-26.

I890, 9I. Paraconchoecia gracilis Claus, I890, S. I5; I891, S. 66, Taf. I2.

I898. Conchoecia quadrangularis Aurivillius, I898. S. 42.

Stat. I48. -2 ㅇ.

Stat. 203. -2 .

Stat. $243 .-2$ ㅇ․

Verbreitung: Atlantik, Indik.

6. Conchoecia procera G. W. Müller.

I89I. Conchoecia variabilis (pr. prt.) G. W. Müller, 1891, S. 273, Taf. 28, fig. $27,38$.

I 894. Paraconchoecia oblonga Claus, I894, S. 3, Taf. 3, fig. 21 -23 (Non P. obl. Claus I890, 9I).

I894. Conchoecia procera G. W. Müller, I894, S. 228, Taf. 6, fig. 47, 48, 50-58.

1906. Conchoecia procera G. W. Müller, I906, S. 7I, Taf. I3 (9), fig. 37-47; Taf. I4 (10), fig. 3-6.

Stat. I4I. - 5 Indiv.

Stat. 203. -2 ㅇ.

Stat. 243. -7 Indiv.

Stat. 276. - I .

Verbreitung: Atlantik, Indik.

\section{Conchoecia acuminata (Claus).}

I890, 91. Conchoecetta acuminata Claus, I890, S. 16; 1891, S. 67, Taf. I3; Taf. I4.

1906. Conchoecia acuminata G. W. Müller, 1906, S. 76, Taf. I5 (I I), fig. I7-23.

1906. Conchoecia acuminata pro parte W. Vavra Igo6, S. 43, Taf. 3, fig. 44-48.

I894. Halocypris elongata Th. Scott, I894, S. I4I, Taf. I 5, fig. I, 2, $27,30$.

Stat. I48. - I Indiv.

Stat. 185. - 3 Larven.

Stat. 276. - I 7 , $100^{7}$.

Stat. 282. -2 ㅇ․

Verbreitung: Atlantik, Indik, Pacifik (?)

8. Conchoecia parthenoda G. W. Müller.

1906. Conchoecia parthenoda G. W. Müller, 1906, S. 78, Taf. I6 (I2), fig. 24-29.

Stat. $276 .-2$ \%.

Verbreitung: Atlantik, Indik.

9. Conchoecia rotundata G. W. Müller.

1891. Conchoecia rotundata G. W. Müller, I89I, S. 275, Taf. 28, fig. 4I-43; Taf. 29, fig. 44. 1906. Conchoecia rotundata G. W. Nüller, 1906, S. S3, Taf. I7 (13), fig. 23-24.

Stat. I94. - I ㅇ.

Stat. $243 .-8$ Indiv.

Verbreitung: Atlantik, Indik, Pacifik. 
10. Conchoecia curta Lubbock.

1863. Conchoecia curta Lubbock, I860, S. I88, Taf. 29, fig. 3I, $32\left(0^{7}\right)$.

1906. Conchoecia curta G. W. Müller, I906, S. 86, Taf. 30 (26), fig. I-9.

1863. Halocypris rostrata Lubbock 1860, S. 189, Taf. 29, fig. 33,34 ( $(9)$.

I887. Halocypris clausii G. O. Sars, I887, S. 87, Taf. II, fig. 7-IO; Taf. I4, fig. 6-I8.

I890. Microconchoecia clausii (? var. reticulata?) Claus, I890, S. 23.

I891. Microconchoecia clausii (? var. reticulata, similis und spinulosa?) Claus, I89I, S. 73,

Erklärung von Taf. 20 und Taf. 20, fig. 7-23.

I894. Conchoecia clausii G. W. Müller, I894, S. 230, Taf. 6, fig. 2I, 23-30; Taf. 8, fig. 3 I, 32.

Stat. 243. - IO Indiv.

Verbreitung: Atlantik, Indik, Pacifik.

\section{I. Conchoecia bispinosa Claus.}

I890, 91. Conchoecia bispinosa Claus, I890, S. I0; I891, S. 59, Taf. 5; Taf. 6, fig. I; Taf. 8, fig. 7, 8. 1906. Conchoecia bispinosa G. W. Müller, 1906, S. 90, Taf. I8 (14), fig. I2-19.

?1906. Conchoecia secernenda W. Vavra, I906, S. 59, Taf. 6, fig. I21-127 ${ }^{1}$ ).

Stat. 66. - I 9 .

Stat. I4I. -2 Q.

Stat. $148 .-9$.

Stat. $185 .-4$ Indiv.

Stat. 203. -2 ㅇ․

Stat. 243. - I 9 .

Stat. 276. - I $0^{7}$.

Alle Tiere maassen 2,4-2,6 mm., zeigten also geringe Unterschiede in der Grösse, während sonst die Grösse sehr variabel († r,74-3,o mm.).

Verbreitung: Atlantik, Indik.

I 2. Conchoecia striola G. W. Müller.

I89I. Conchoecia striata G. W. Müller, I89I, S. 270, Taf. 28, fig. 12-18 (nom. praeocc., non C. striata Claus I890).

1906. Conchoecia striola G. W. Müller, 1906, S. 91, Taf. I8 (I4), fig. I1, 20-24.

1906. Conchoecia millleri Juday, I906, S. 24, Taf. 5, fig. 5-7, Taf. 6, fig. I-5.

Stat. I4I. - I $ᄋ$.

Stat. 203. $-\mathrm{I}$ \%.

Stat. $216 .-1$ ㅇ.

Stat. 243. - I क, I O?.

Verbreitung: Atlantik, Indik, Pacifik.

\section{I3. Conchoecia atlantica (Lubbock).}

1856. Halocypris atlantica Lubbock, 1856, S. 28, Taf. I2, fig, $\mathrm{I}-8$ (juv.).

non I880. Halocypris atlantica G. S. Brady, I880, S. I64, Taf. 40, Taf. 4I, fig. II, I2.

1891. Conchoecia cuneata C. W. Müller, I89I, S. 27I, Taf. 28, fig. II, 21, 22, 25.

1) W. Vavra trennt 1. c. die grösseren Formen von C. bispinzosa als C. secernenda ab; auf die Berechtigung dieser Trennung werde ich an anderer Stelle zurückkommen. 
I895. Conchoecia agassizii G. W. Müller, I895, S. 166, Taf. 2, fig. I-7, I2-I4, 16-I8.

I894. Halocypris torosa Th. Scott, I894, S. I42, Taf. I5, fig. 3, 4, 32, 35, 37.

1906. Conchoecia atlantica G. W. Müller, 1906, S. 92, Taf. 5, fig. 6, 7, Taf. 19, fig. 17-28.

Stat. 14I. - 3 Indiv.

Stat. I48. -4 Indiv.

Stat. I85. - I3 Indiv.

Stat. 203. - I 8 Indiv.

Stat. 243. - I7 Indiv.

Stat. 276. - I0 Indiv.

Die $q$ maassen $3,6-3,8$, die $\sigma^{7} 3,5 \mathrm{~mm}$., so dass die Thiere etwas grösser wie die des Indik, beträchtlich kleiner als die des Pacifik.

Verbreitung: Atlantik, Indik, Pacifik.

I4. Conchoecia loricata (Claus).

I894. Conchoecissa loricata Claus, I894, S. 4, Taf. 3, fig. 24-30.

1906. Conchoecia loricata G. W. Müller, 1906, S. 95, Taf. 22 (18) fig. I-9.

Stat. I4I. - I ㅇ.

Stat. $185 .-$ I ㅇ․

Stat. 243. - I O , I $0^{3}$.

Verbreitung: Atlantik, Indik.

15. Conchoecia ctenophora G. W. Müller.

1906. Conchoecia ctenophora G. W. Müller, 1906, S. 96, Taf. 22 (I8), fig. 16-20, 29.

Stat. $\mathrm{r}_{4} \mathrm{I}$. - I ㅇ.

Stat. $185 .-1$ o

Stat. 243. - 10 \%

Verbreitung: Atlantik, Indik.

I6. Conchoecia lophura G. W. Müller.

1906. Conchoecia lophura G. W. Müller, I906, S. 99 Taf. 20 (I6), fig. I-IO.

Stat. I4I. - I O, 2 O'.

Stat. 148. - I $\sigma^{3}$.

Stat. $185 .-1$ Q.

Stat. 243. - I .

Verbreitung: Atlantik, Indik.

I7. Conchoecia machrocheira G. W. Müller.

1906. Conchoecia macrocheira G. W. Müller, I906, S. IoI, Taf. 2I (17), fig. I-9.

1906. Conchoecia hamata W. Vavra, I906, S. 52, Taf. 5, fig. 92-99.

Stat. I4I. - I O?.

Stat. I85. - I 9 , I $0^{7}$.

Stat. 243. - I $0^{7}$.

Verbreitung: Atlantik, Indik. 
I8. Conchoecia subarcuata Claus.

I890, 9 I. Conchoecia subarcuata Claus, I890, S. 9, I89I, S. 58, Taf. 3, fig. 3-9; Taf. 4. I906. Conchoecia subarcuata G. W. Müller, 1906, S. I02, Taf. 21 (I7), fig. Io-I6, 19. 1890, 9I. Conchoecia striata Claus, 1890, S. I2, I891, S. 62, Taf. 8, fig. I-6.

Stat. 243. - I $0^{7}$.

Stat. $276 .-2$ ㅇ.

Verbreitung: Atlantik, Indik.

19. Conchoecia magna Claus.

1874. Conchoecia magna Claus, I874, S. 6, Taf. I, fig. $6 c$; Taf. 2, fig. I6, I8.

1906. Conchoecia magna G. W. Müller, I906, S. I03, Taf. 2I (I7), fig. I7, I8, 20, 26.

i887. Conchoecia tetragona G. O. Sars, I887, S. 82, Taf. II, fig. 5, 6; Taf. I3, fig. 5-9.

Stat. I 4 I. -9 ㅇ, I $\sigma^{3}$.

Stat. 148. - 3 क, 10 \%

Stat. 243. - 3 ㅇ.

Stat. 276. - I $0^{7}$.

Verbreitung: Atlantik, Indik, Pacifik.

20. Conchoecia spinirostris Claus.

I874. Conchoecia spinirostris Claus, I874, S. 6, Taf. I, fig. I, $6 a, 8$, Taf. 2, fig. II, I4, I5. 1906. Conchoecia spinirostris G. W. Müller, 1906, S. 104, Taf. 22 (18), fig. 21-23, 25-28.

I887. Conchoecia pellucida G. O. Sars, I887, S. 8o, Taf. II, fig. I-4; Taf. I2; Taf. I3, fig. I-4. I890, 91. Conchoecia porrecta Claus, I890, S. I2, I89I, S. 6I, Taf. 7.

Stat. I4I. - I O ${ }^{7}$.

Stat. 243. -2 o?

Stat. $276 .-2$.

Verbreitung: Atlantik, Indik, Pacifik.

21. '? Conchoecia mollis G. W. Muiller.

1906. Conchoecia mollis G. W. Müller, I906, S. I06, Taf. 24 (20), fig. I-IO, I3.

Stat. I4I. - I .

Stat. $185 .-3$ ㅇ.

Stat. 203. - I $Q$.

Stat. 230. -2 ㅇ.

Stat. $243 .-2$ ㅇ.

Da sich die of der verschiedenen sehr ähnlichen Arten (mollis, amblypostha, kampta, acanthophora), nicht sicher unterscheiden lassen, und nur $q$ vorlagen, lässt sich nicht feststellen, zu welcher dieser Arten die Thiere gehören.

22. Conchoecia plinthina G. W. Müller.

? I880. Halocypris imbricata Brady, I880, S. I67, Taf. 4I, fig. 2, io (pr. prt.). 1906. Conchoecia plinthina G. W. Müller, I906, S. I 16, Taf. 27 (23) fig. I-6, 9, I0, 20. Stat. 185. - I $0^{7}$.

Verbreitung: Atlantik, Indik. 
23. Conchoecia ametra G. W. Müller.

1906. Conchoecia ametra 1906, S. I17, Taf. 27 (23), fig. I1, 12, 14, 17-19.

1906. Conchoecia insignis W. Vavra, 1906, S. 56, Taf. 5, fig. 105-107; Taf. 6, fig. 108-II3.

1906. Conchoecia ritteri Juday, 1906, S. 25, Taf. 6, fig. 6-8, Taf. 7, fig. I, 2.

Stat. I4I. - 3 Ind.

Stat. 148. - I Ind.

Verbreitung: Atlantik, Indik, Pacifik.

24. Conchoecia imbricata (G. Brady).

I880. Halocypris imbricata (pr. pt.) G. Brady, I880, S. I67, Taf. 4I, fig. I-IO; Taf. 42, fig. I-8.

189I. Conchoecia imbricata G. W. Müller, I89I, S. 277.

I906. Conchoecia imbricata G. W. Müller, 1906, S. r18, Taf. 28 (24), fig. I-6.

I898. Conchoecissa imbricata Brady, I898, S. 96.

I890, 9I. Conchoecissa armata Claus, I890, S. I9; I891, S. 70, Taf. 16, I7, I8.

Stat. I28. - I ㅇ.

Stat. I4I. -2 .

Stat. $276 .-5$ Indiv.

Verbreitung: Atlantik, Indik, Pacifik.

25. Conchoecia leptothrix G. W. Müller.

1906. Conchoecia leptothrix G. W. Müller, I906, S. 122, Taf. 27 (25), fig. 20-26.

Stat. I4I. -8 Indiv.

Stat. I48. $-30^{7}$.

Stat. I $85 .-$ I 9 .

Stat. 203. -2 .

Verbreitung: Atlantik, Indik.

26. Conchoecia daphnoides (Claus).

I890, 9I. Conchoecilla daphnoides Claus, I890, S. I8, I89I, S. 68, Taf. I5 (O' juv.).

I90 I. Conchoecia daphnoides G. W. Müller, Igor, S. 6, (o', ()).

1906. Conchoecia daphnoides G. W. Müller, I906, S. I26, Taf. 3I (27), fig. I-I5.

1896. Conchoecilla lacerta Brady \& Norman, I896, S. 697, Taf. 62, fig. I-4, Taf. 65, fig. I-Io (P).

Stat. 243. - I $\sigma^{\top}$.

Verbreitung: Atlantik, Indik, Pacifik.

27. Conchoecia sibogae n. sp. Taf. I, Fig. IO-20.

Stat. I4I. - I \&, I $\sigma^{7}$, I juv.

Stat. 143. - I .

Stat. 148. - 2 ㅇ, I $\sigma^{7}, 3$ juv.

Stat. 185. - I 8?.

Schale ziemlich derb, Höhe etwa $1 / 2$ der Länge, beim $\sigma^{7}$ sehr wenig, beim $q$ deutlich nach vorn verschmälert, Schulterwulst ziemlich vortretend, aber nicht scharfkantig erhoben. Hinterrand 
und Dorsalrand bilden einen Winkel, der wenig kleiner ist als ein rechter, seine Ecke ist beiderseits in eine kleine, aber deutliche Spitze ausgezogen, dieselbe ist links etwas grösser wie rechts. Hinterrand annähernd gerade, er bildet mit dem Ventralrand einen stumpfen Winkel, dessen Ecke links etwas abgerundet ist, rechts wird die Ecke gebildet oder überragt von einem kurzen und warzenartigen Fortsatz, welcher die Mündung der rechten unsymmetrischen Drüse ${ }^{1}$ ) aufnimmt. Oberfläche mit ziemlich auffälliger Skulptur; dieselbe besteht in der Hauptsache aus einer dichten Streifung. Die Streifen verlaufen dem Dorsal- und Ventralrand annähernd parallel, steigen in der ventralen Hälfte etwas nach vorn auf; die einzelnen Längslinien sind durch Querbalken verbunden, wodurch eine rechteckige oder rhombische Felderung entsteht, an deren Stelle eine unregelmässige polygonale Felderung treten kann, so besonders nahe der hinteren ventralen Ecke. Die Querbalken können sich derart anordnen, dass sie eine gerade Linie bilden, dann entsteht ein zweites System von parallelen Linien, doch sind diese Linien nicht so deutlich, wie die stets überwiegenden Längsstreifen.

Die Skulptur kann im Bereich der ganzen Schale deutlich sein, meist ist sie nahe der hinteren dorsalen Ecke undeutlich oder ganz ausgelöscht, ferner kann sie in einem mittleren breiten Streifen undeutlich sein. Die rechte unsymmetrische Drüse mündet, wie gesagt, an der hinteren ventralen Ecke auf einem warzenartigen Fortsatz, die linke nahe der hinteren dorsalen Ecke. Laterale Eckdrüse deutlich, ihre Mündung sehr weit auf die mediale Seite verschoben (Fig. II). Dorsale mediale Drüse in beiden Geschlechtern vorhanden, beim ơ umfangreicher, sie mündet in einiger Entfernung von der hinteren dorsalen Ecke. Die Mündunge der medialen Drüsenzellen des Hinterrandes deutlich, durch deutliche Bogenlinien verbunden.

Frontalorgan des $\sigma^{7}$ (Fig. IO): Endstück umfangreich, etwa $3 / 4$ so lang wie der Stamm, deutlich abgegrenzt, herabgebogen, dicker wie der Stamm, distal verjüngt, terminal zugespitzt, die Spitze abgestumpft, Dorsal- und Ventralrand in ziemlichen Umfang mit starken Börstchen besetzt. I Antn. des $\%$ : der Stamm annähernd so lang wie der des Frontalorgans, und etwa $1 / 2$ so lang wie die terminale Hauptborste; die Sinnesschläuche deutlich kürzer wie der Stamm.

Frontalorgan des ㅇ: (Fig. 15, I 7) das Endstück ziemlich kurz, es misst etwa $1 / 3$ des Stammes. Im Profil ist das terminale $1 / 8$ stark verschmälert, es ist durch einen einspringenden Winkel am Ventralrand scharf abgegrenzt. Der Dorsalrand ist etwa auf halber Länge winklig eingedrückt, der Ventralrand des breiteren Basalstückes S-förmig geschwungen und in ganzen Umfang ziemlich dicht mit Börstchen besetzt; die Spitze des Ganzen abgerundet.

Haupt- und Nebenborsten der I Antn. (Fig. I6) annähernd gleich lang, die Nebenborsten wenig kürzer, die Hauptborste etwa im mittlerer $3 / 3$ mit einer Doppelreihe basalwärts gerichteter, dicht stehender Plättchen besetzt (Fig. I 2); (da an diesen Plättchen der distale Rand kräftig, der Rest zart, zudem zum Teil vom benachbarten Blättchen bedeckt ist, erhält man zunächst das Bild einer Reihe von Börstchen). Proximale Nebenborste mit deutlicher Schwiele, distale mit zerstreuten, distal gerichteten Börstchen. Sinnesschläuche kurz.

Innenast der 2 Antn. (Fig. 18-20): die Sinnesschläuch erreichen in beiden Geschlechtern annähernd $1 / 2$ der Länge der längsten Borste. Am rechten Hakenglied bilden distaler und 
proximaler Ast einen rechten Winkel mit wenig abgerundeter Ecke, der proximale mit zwei Zähnen, der distale ziemlich stark gebogen, so dass sein Endstück dem proximalen Ast annähernd parallel, etwa noch einmal so lang wie der proximale Ast; links ist der betreffende Winkel deutlich grösser wie ein rechter, der distale Ast bildet einen flachen Bogen.

Länge des o $2,8-3,0$, des $0^{7} 2,75 \mathrm{~mm}$.

Die Art duirfte der C. rhynchena G. W. Müller (1906, S. I I 3, Taf. 26 [22] fig. I 7-25) nächst verwandt sein, und gilt das 1. c. S. Io6 iber die systematische Stellung von rhynchena Gesagte auch für C. sibogae.

28. Conchoecia concentrica n. sp. Taf. I, Fig. I-9.

Stat. $37 .-1$
Stat. $276 .-10^{7}$.
Stat. $282 .-2$ \%.

Schale ziemlich derb, kurz und hoch, Höhe deutlich grösser als $1 / 2$ der Länge, beim ot nicht, beim \& etwas nach vorn. verschmälert; Schulterwulst stark vortretend, stumpfkantig, Hinterrand und Dorsalrand bilden mit einander etwa einen rechten Winkel, dessen Ecke rechts in eine kurze, undeutliche Spitze ausgezogen ist, links fehlt diese Spitze fast ganz. Hinterrand annähernd gerade, hintere ventrale Ecke wenig abgerundet, Ventralrand schwach gewölbt. Die Oberfläche zeigt eine sehr deutliche und ziemlich dichte Längsstreifung; die Streifen biegen, abgesehen von einer schmalen dorsalen Partie, deren Grenze die Kante des Schulterwulstes bildet, vorn deutlich dorsalwärts um. Die Streifung scheint nahe dem Hinterrand ausgelöscht, bei genauerer Untersuchung bemerkt man, dass hier an ihre Stelle eine polygonale Felderung tritt, die sich aber leicht der Beobachtung entzieht. Unsymmetrische Drüsen an gewöhnlicher Stelle, laterale Eckdrüse (Fig. 9) vorhanden, sie mündet lateral auf der Fläche in geringer Entfernung vom Schalenrand, rechts etwas dorsal von der unsymmetrischen Drüse (diese Drüse ist wegen der Schalenskulptur schwer nachzuweisen).

Frontalorgan des $\mathcal{O}^{1}$ ) mit ziemlich umfangreichem Endstück (Fig. 9); dasselbe misst über $1 / 2$ des Stammes, es ist deutlich abgegrenzt, wenig dicker als der Stamm, schwach S-förmig gebogen, sehr wenig herabgebogen, das distale $1 / 3$ ist deutlich schmaler als der Rest, am Ventralrand durch einen einspringenden Winkel abgegrenzt, terminal zugespitzt; der Ventralrand ist bis zu dem genannten Winkel ziemlich dicht mit kräftigen Börstchen besetzt, annähernd in gleichem Umfang der Dorsalrand. Hauptborste und Sinnesschläuche der I Antn. des $q$ waren bei den untersuchten Individuen sehr defect.

Frontalorgan des $\sigma^{7}$ (Fig. 8) mit ziemlich kurzem, dickem, deutlich dorsalwärts gekrümmtem Endstück; dasselbe war bei dem einzigen untersuchten Individuum etwas defect, liess aber immerhin in der Hauptsache die Form erkennen. Hauptborste der I Antn. des $\sigma^{7}$ (Fig. 7, 8) mit einer Doppelreihe steil abstehender ziemlich schlanker Spitzen; dieselben stehen ziemlich dicht, nehmen basalwärts wenig an Länge zu. Die Reihe nimmt etwas weniger als $1 / 3$ der

I) In dem Material von Stat. 282 fanden sich 2 leere Schalen der Art und zwei aus der Schale gelöste Körper weiblicher Thiere, die nach ihrer Grösse sehr wohl zu den Schalen passten. Ebenso in Stat. 37. Ich betrachte die Zusammengehörigkeit als hinreichend gesichert, beschreibe das $\{$ nach den ausgelösten Körpern; immerhin muss die Möglichkeit eines Irrthums zugestanden werden. 
Gesammtlänge der Borsten ein. Nebenborsten etwa so lang wie die Hauptborste, die proximale mit kleiner Schwiele. Sinnesschläuche kurz (der proximale war defect).

Innenast der 2 Antn. des $\sigma^{7}$ (Fig. 3-5): die Sinnesschläuche kurz, sie messen höchstens 1/3 der längsten Borste, sind wohl beträchtlich kürzer (die längste Borste war nỉcht vollständig erhalten); rechtes Hakenglied sehr umfangreich, sein distaler Art so lang wie das Basalglied, und deutlich länger als $1 / 2$ der Sinnesschläuche, distaler und proximaler Ast bilden einen spitzen Winkel mit gerundeter Ecke, der distale Ast gebogen, länger als der proximale. Linkes Hakenglied klein und schwach entwickelt, spitzwinklig, die Ecke des Winkels wenig abgerundet, der distale Ast gerade. Penis sehr kurz und breit.

Schale des o r, 6 , des $\sigma^{7}$ r,45 mm.

Ich vermag keine deutlichen verwandtschaftlichen Beziehungen zu einer der bekannten Arten zu erkennen; manche Charactere sprechen für eine Verwandtschaft mit C. serrulata. 


\section{CYPRIDINIDAE.}

Diagnose vergl. G. W. Müller, I 894, S. 203.

Die Cypridiniden waren in dem Siboga-Material durch eine grosse Zahl von Individuen, welche 25 Arten angehören, vertreten; die Mehrzahl dieser Arten ist neu.

Ich vertheile die Gattungen der Cypridiniden auf 4 Unterfamilien: Cypridininae, Philomedinae, Sarsiellinae, Cylindroleberinae; von diesen war die der Philomedinae im SibogaMaterial nicht vertreten.

\section{Cypridininae,}

Schale mit deutlichem Rostrum; I Antn. 8 gliedrig, das letzte Glied klein, schwer nachweisbar, bisweilen fehlend (?), Sinnesborste des 5 Gliedes in beiden Geschlechtern gleich oder sehr ähnlich gestaltet, beim $\sigma^{7}$ zwei Borstèn des letzten Gliedes meist mit Saugscheiben bewaffnet. Innenast der 2 Antn. sehr verschieden gestaltet, häufig in beiden Geschlechtern rudimentär, seltner beim $\sigma^{\pi}$ als Greiforgan entwickelt. Die folgenden Gliedmaassen in beiden Geschlechtern gleich gestaltet (ausnahmsweise der Putsfuss etwas verschieden?).

Maxille kräftig, mit 3 Kaufortsätzen und starkem, die Kaufortsätze weit überragendem Taster. 2 Maxille mit umfangreichem Kautheil, dessen Spitze (2 ${ }^{\text {tes }}$ Glied) 2 Gruppen von mindestens je 3 zahnartig gestalteten Fortsätzen trägt. Oberlippe umfangreich, mit wohl entwickelter Oberlippendrüse.

Die Unterfamilie umfasst Formen, die sich durch auffallende anatomische Merkmale unterscheiden (Vorhandensein von Rückenfalten (Kiemen?) bei Cypridina hilgendor $f$ o ${ }^{7}$ und Cypridina asymmetrica o', auffallende Behaarung zweier Borsten der I Antn. bei 'C. hirsuta o', Greiforgane bei Codonocera $\sigma^{7}$ etc.), so dass eine Auflösung in verschiedene Gattungen wohl erwünscht erscheint. Abgetrennt sind zur Zeit von Cypridina s. str. die Gattungen Crossophorus Brady, charakterisirt durch die Gestalt der Furca und den Innenast der 2 Antn. des or, und Gigantocypris G. W. Müller, charakterisirt durch die dünnhäutige, blasig aufgetriebene, in grossem Umfang verschmolzene Schale, sowie durch das Frontalorgan. Die Existenzberechtigung dieser beiden Gattungen scheint mir unzweifelhaft. Ähnliches gielt von Codonocera Brady (1902, p. I88). 
Die Gattung umfasst eine ganze Reihe von sehr ähnlichen Arten, welche sich durch verschiedene Merkmalen von den typischen Vertretern der Gattung Cypridina unterscheiden (vergl. unten die Gattungsdiagnose). Die Gattung Pyrocypris G. W. Müller (I89 I, p. 230) = Eupathistoma Brady (1898, p. 437) steht der Gattung Cypridina s. str. viel näher als die genannten, man kann in Zweifel daruber sein, ob nicht manche Vertreter von Cypridina ihr näher verwandt sind als anderen Vertretern der Gattung, und ob ihre Abtrennung die natürliche Verwandtschaft zum Ausdruck bringt. Auf jeden Fall vereinigt sie eine grössere Zahl nahe verwandter Form, lässt sich auch scharf charakterisiren. Anders ist es bei den folgenden Gattungen: Monopia Claus (1873, p. 225) = Eumonopia Claus (189 $\alpha$, p. ro - die Namenänderung war durchaus überflüssig) charakterisirt durch das umfangreiche Frontalorgan. Berücksichtigen wir nur das Frontalorgan, so reissen wir nächst verwandte Formen, wie z.B. C. flaveola Claus und favus Brady $=$ Cypridinotes favus Brady (1902, p. 187) auseinander. BRADY hat 1.c. die Gattung Cypridinotes aufgestellt, doch beruht seine Charakteristik ganz oder fast ganz auf Beobachtungsfehlern: an der Maxille sind die auch bei anderen Vertretern der Gattung Cypridina kurzen Kaufortsätze der Maxille abgerissen, der schlanke Maxillartaster allein gezeichnet, er findet sich in gleicher Form z.B. bei Cypridina asymmetrica, die eigenthümlich knotige Bewaffnung der Zahnborsten des I Thorabeines (2 Maxille) dürfte das Resultat einer perspectivischen Verkürzung sein, beim 2 Maxillarfuss dürften sich die beiden dicken nach hinten gerichteten Borsten (vergl. Taf. 6, Fig. 7) derart aneinandergelegt haben, dass sie für einen oberflächlichen Beobachter wie ein Fortsatz erscheinen. Wollen wir die fragliche Form aus der Gattung Cypridina entfernen, wofür allerdings BRADy's Diagnose keinerlei Anhalt gewährt, so müssen wir sie mit Monopia vereinigen, doch müsste dann die Diagnose dieser Gattung ganz anders lauten.

Wie oben gesagt, erscheint eine weitere Auflösung der Gattung Cypridina s. str. dringend erwuinscht, doch gestattet der heutige Zustand unserer Kenntniss der betreffenden Formen eine Inangriffnahme dieser Aufgabe kaum.

Cypridina M. Edwards.

Diagnose vergl. G. W. MüLler, I894, p. 204.

I. ? Cypridina hilgendorfi G. W. Müller.

I891. Cypridina hilgendorfi G. W. Müller, 189I, S. 228, Taf. 25, Fig. 9, Taf. 26, fig. I-3; Taf. 27 , fig. 23,30 .

Stat. 99. -2 juv.

Verbreitung: Pacifik.

2. Cypridina castanea Brady.

I898. Cypridina castanea Brady, I898, S. 88, Taf. I6, fig. I-4.

I906. Cypridina castanea G. W. Müller, I906, S. I30, Taf. 5 (I) fig. I, 2; Taf. 33 (29), fig. II-I6; Taf. 34 (30), fig. 10-I3.

1906. Cypridina obesa W. Vavra, 1906, S. 67; Taf. 7, fig. 132b- 142.

Stat. I4I. - I juv.

Verbreitung: A tlantik, Indik. 
3. Cypridina asymmetrica n. sp. Taf. 6, Fig. I-I2.

Stat. I6. - 2. $9,20^{7}, 6$ juv.

Stat. 40. - I jux.

Stat. 47. - I Indiv.

Stat. 66. - 3 Indiv.

Stat. 96. - 3 Indiv.

Stat. 99. - 9 Indiv.

Alle Fänge sind planktonische an Stellen von weniger als roo M. Tiefe.

Schale des $\sigma^{7}$ : Höhe annähernd ${ }^{2 / 3}$ der Länge. Dorsalrand stark gewölbt, die Wölbung in der Mitte etwas abgeflacht, Ventralrand ebenfalls stark gewölbt, Hinterende zugespitzt, die Spitze links deutlich, rechts undeutlich durch einen einspringenden Winkel gegen den Dorsalrand abgegrenzt, gegen den Ventralrand nicht abgegrenzt. Rostrum ohne vordere Ecke, über der ventralen Spitze eine flache Warze. Ventrale Spitze deutlich, stark ventralwärts gerichtet, wenig abgerundet. Incisur ziemlich klein, im Grund gerundet. Ventralwärts von den Incisur findet sich rechts eine umfangreiche Warze, die durch eine deutliche Bucht gegen den Ventralrand abgegrenzt ist. Links eine ähnliche Warze, aber viel weniger auffällig. Die Oberfläche trägt grössere und kleinere, scharf conturirte, runde Gruben; die grösseren sind ziemlich regelmässig angeordnet, sie sind in einer breiten Randpartie deutlich, in der Mitte werden sie undeutlich oder verschwinden ganz; die kleineren finden sich gleichmässig über die ganze Schale zerstreut; zwischen grösseren und kleineren finden sich keine Übergänge. Da diese Gruben die oberflächliche undurchsichtige Schicht der Schale durchsetzen (vergl. G. W. MÜLLER, I 894, p. 95), so erscheinen sie (besonders die grösseren) bei geeigneter Behandlung (in Canadabalsam) bei auffallenden Licht als sehr auffällige dunkle Punkte auf kreideweissem Grund. Im Grunde von beiderlei Gruben mündet ein Porencanal. Ferner zeigt die Schale ein wenig auffällige Felderung (Fig. 3), die ihr eine schuppiges Aussehen verleiht, nahe den Rand als Streifung erscheint; die Felder gruppiren sich ziemlich regelmässig um die grösseren, weniger regelmässig um die kleineren Gruben. Die Schale ist farblos, nur nahe dem Rücken finden sich meist verzweigte Pigmentzellen.

I Antn.: die längsten terminalen Borsten in beiden Geschlechtern etwa so lang wie die Antenne, die Bewaffnung der Borsten (Fig. 9) des $\sigma^{7}$ von gewöhnlicher Form, die Seitenzweige tragen ziemlich zahlreiche $(6-7)$ kleine Saugscheiben, zu denen noch eine basale Spitze ohne Scheibe zu kommen pflegt.

Innenast der . 2 Antn. (Fig. I I) in beiden Geschlechtern ähnlich gestaltet, schlank, ziemlich gestreckt, deutlich zweigliedrig, terminal mit umfangreicher Borste. Das I Glied des Aussenastes ist an seinem Vorderrand mit Gruppen kleiner Haare besetzt, das $2^{\text {te }}$ Glied trägt eine kurze, mit kräftigen Dörnchen bewehrte Borste.

An der Maxille sind die Kaufortsätze auffallend kurz, der Taster lang und schlank. Putsfuss mit einer geringen Zahl von Borsten, terminal, in nächster Nähe der Zange etwa 6, proximal von der Zange etwa Io; die Zange kräftig, sie besteht aus einem unbeweglichen, schnabelartig gebogenem Ast, der mit theils schlanken, theils dickeren Zähnen bewaffnet ist; ihm steht ein schlanker, beweglicher, ebenfalls mit Spitzen bewehrter Ast gegenüber. Furca (Fig. 4) schlank, jeder Ast mit 5 wenig gebogenen Dornen, welche schnell und gleichmässig an Grösse abnehmen. Rücken des or (Fig. 4) mit 6 deutlichen Falten, der des $q$ glatt. 
Oberlippe mit 3 umfangreichen Fortsätzen, einem vorderen unpaaren, welcher 6 Warzen (I Paar am Hinterrand, davor 4 unpaare) trägt, und 2 hinteren paarigen, deren jeder aus einem grossen vorderen und 2 oder 3 kleineren hinteren Zipfeln besteht. Paariges Auge und Frontalorgan wohl entwickelt, in beiden Geschlechtern gleich gross. Im Körper finden sich verzweigte Pigmentzellen zerstreut, besonders in der Umgebung des Mundes und im 2 Thoraxbein.

Länge des ${ }^{2} 2,3$, des $\sigma^{7} 2, \mathrm{I} \mathrm{mm}$.

Die Art steht der Cypridina bairdii Brady (1866, p. 387, Tab. 62, fig. 7 und 1897 , p. 88, Tab. 26, fig. 22, 23) sehr nahe, so dass ich zunächst beide fuir identisch hielt, doch unterscheiden sich beide Arten in folgenden Punkten: Bei C. bairdii ist der Dorsalrand stärker gewölbt, der Fortsatz ventral von der Incisur ist rechts bei beiden Arten ungefähr gleich stark entwickelt, links bei $C$. asymmetrica nicht ganz, bei bairdii ganz unterdrückt. Beim Rostrum scheinen ähnliche Unterschiede zu bestehen, doch ist hier BRADY's Darstellung nicht ganz klar. Die Gruben der Schalenoberfläche sind bei C. bairdii grösser, deutlicher, finden sich auf der ganzen Schalenoberfläche, verfliessen am Rand zu undeutlichen Streifen.

\section{Cypridina hesperida n. sp. Taf. 3, Fig. $2 \mathrm{I}-28$.}

Stat. I8I. - I 9 .

Schale des $q$ gestreckt, Höhe deutlich grösser als $1 / 2$ der Länge, Dorsal- und Ventralrand stark gewölbt, der letztere schwächer, besonders in seiner hinteren Hälfte. Rostrum gerundet, ohne Andeutung einer vorderen oder ventralen Ecke, Incisur schmal. Hinterer Fortsatz wohl entwickelt, ziemlich spitz, sein Dorsalrand ist (bei der ganzen Schale) etwa gerade, er bildet mit dem Dorsalrand der Schale eine einspringenden Winkel mit deutlicher Ecke (Fig. 23). Isoliren wir die Schalen, so zeigt die linke (Fig. 2 I) einen breiteren, terminal gerade abgestutzten, die rechte (Fig. 25) einen schmaleren terminal abgerundeten Fortsatz; die linke hat im Grunde des W'inkels eine Grube, in welche ein Fortsatz der rechten passt. Oberfläche nahe dem Rand mit wenig auffälligen kleinen Gruben. Von den Borsten der I Antn, sind die längsten etwa so lang wie die Gliederreihe, keine von denen des letzten Gliedes ist auffällig behaart. (In der Bearbeitung der Valdivia-Ostrakoden berichtete ich (1906, p. I 3I, I32) über eine $C$. hesperida augenscheinlich nahe verwandte Art, Cypridina hirsuta, bei der beim allein bekannten $\sigma^{7}$ zwei Borsten des letzten Gliedes an der Basis stark behaart sind. Aus dem Vergleich mit $C$. hesperida schloss ich, dass es sich um ein secundäres Geschlechtsmerkmal handelt, weise auch hier darauf hin, dass das $\sigma^{7}$ von $C$. hesperida voraussichtlich eine auffallende Behaarung zweier terminaler Borsten zeigt). Innenast der 2 Antn. rudimentär, mit 3 kurzen Borsten. Die Oberlippe (Fig. 27) trägt am Vorderrand einen langen, unpaaren Zapfen, der in 2 hintereinander liegende Spitzen endigt; der dahinterliegende Theil zeigt keine deutlichen Fortsätze, nur kurze undeutliche Warzen. Der Putsfuss endigt mit kammförmig bewaffneter Spitze, der keine deutliche Spitze gegenüber steht. Das Endstück ist nicht oder nur undeutlich kopfartig abgesetzt. Er trägt etwa I 2 typisch gegliederte Borsten, die sich auf das terminale $1 / 6$ des Beines beschränken.

Furca mit 9 schlanken, wenig gebogenen, am Hinterrand grob gesägten Dornen. Die Dornen nehmen gleichmässig an Grosse und Umfang ab, alle sind durch eine Naht vom Stamm getrennt. Länge des $ᄋ$ 2,0 mm., $\sigma^{\top}$ unbekannt. 
5. Cypridina flaveola Claus. Taf. 3, Fig. 28.

I873. Cypridina monopia Claus, I873, S. 222, Taf. I3, fig. 2I-3I.

I873. Monopia flaveola Claus, 1873, S. 225, 227.

ISgIa. Eumonopia flaveola Claus, I89I, S. IO.

Stat. I06. - I juv.

Stat. IOg. -3 juv.

(Planktonisch an Stellen mit geringer Tiefe).

Leider waren sämmtliche Individuen noch nicht geschlechtsreif. Aus diesem Grund verzichte ich auf eine Darstellung, zumal ich der von CLAus 1.c. gegebenen kaum etwas hinzufügen könnte, beschränke mich darauf, ein Bild des Frontalorgans zu geben, da die Abbildung von Claus keine Vorstellung von der Form, in's besondere von dem Grössenverhältniss des zitzenförmigen Fortsatzes und des Basalstückes giebt. Den von CLaus beschriebenen $T$-förmigen Schlauch habe ich nicht entdecken können, obwohl ich einige Mühe auf das Suchen verwandt habe.

Die Exemplare von Claus stammten von der Insel Palawang, also auch aus dem malayischen Archipel.

\section{Pyrocypris G. W. Müller.}

I891. Pyrocypris G. W. Müller, I89I, S. 230.

I898. Eupathistoma G. S. Brady, I898, S. 437.

Eine artenreiche Gruppe von sehr ähnlichen Formen, die man schon am Habitus mit ziemlicher Sicherheit zu erkennen vermag. Zur Charakteristik der Gattungen mögen folgende Merkmạle dienen: Schale stets gestreckt, das Rostrum stets mit deutlicher ventraler Ecke, der hintere Fortsatz wohl entwickelt, am Dorsalrand deutlich abgegrenzt. I Antn. des o mit 2 Borsten, welche beträchtlich länger sind als die Schale. (Sollen diese Borsten in der Schale verborgen werden, so müssen sie um den Hinterleib herumgeschlagen werden; vergl. Taf. 2, Fig. 7). Die Bewaffnung der Borsten der I Antn. ähnlich wie in der Gattung 'Cypridina, die Haftorgane schwach entwickelt. Beim $q$ sind die Borsten der I Antn. wesentlich kürzer, die längsten wenig länger als die Gliederreihe der I Antn. Der Innenast der 2 Antn. in beiden Geschlechtern rudimentär, aus einer flachen Warze mit 4 oder 5 Borsten bestehend. Putsfuss terminal mit einer Gruppe ziemlich langer gebogener Borsten an Stelle der Zange, resp. des einen Astes derselben, ausserdem mit wenigen (3-6) typischen gegliederten Borsten. Furca mit 9 Dornen an jedem Ast. Oberlippe mit 6 (2 unpaaren vorn, 2 Paaren hinten) fingerartigen Fortsätzen, welche die Mündung der sehr umfangreichen Oberlippendrüse aufnehmen. Die Form der Oberlippe besonders charakteristisch.

Von verschiedenen Vertretern der Gattung ist bekannt, dass sie leuchten (G. W. MülLer, I89 I, p. 244, 1894, p. 108) wahrscheinlich thun es alle Arten. Ich hatte 1.c. als Leuchtorgan, als Organ, welches die leuchtende Materie absondert, die Oberlippendrüse angesprochen. CLAUs (189I, p. I6) widersprach dieser Deutung, meinte die Drisenzellen des Schalenrandes lieferten die leuchtende Materie, eine Anschauung, welche unvereinbar ist mit dem Phenomen des 
Leuchtens, wie es von verschiedenen Autoren beschrieben wird, und das in einem Ausstossen von leuchtender Substanz besteht. Ein kurze Beschreibung des Phenomens bei einem allerdings nicht der Gattung Pyrocypris, sondern Cypridina angehörigen Ostracoden, Cypridina hilgendorfi G. W. Müller, verdanken wir Watanabe (1897, p. 69). Über den Ursprung der leuchtenden Materie sagt er: "The phosphorescent organ of this ostracod is a group of elongated, unicellular, "epidermal glands opening to the exterior symmetrically on either side of the median line, on "the external edge of the upper lip — the glands called by CLAUS, Oberlippendruse in I873". Ich denke, damit ist die Controverse über das Leuchtorgan der Ostracoden entschieden.

Die Abgrenzung der Gattung mag als eine provisorische gelten, da wir innerhalb der Gattung Cypridina (s. str.) Formen finden, die unzweifelhaft Pyrocypris nahe verwandt sind, ohne in der Gattung bei der gegebenen Diagnose Platz zu finden, insofern ist die Abgrenzung keine ganz natürliche. Eine naturgemässe Eintheilung der Cypridininae wird erst möglich sein, wenn wir eine grössere Zahl von Formen genau kennen. Unzweifelhaft bilden die hier unter dem Gattungsnamen Pyrocypris beschriebenen Formen eine natüliche Gruppe, der sich ferner anreihen 5 von mir (I89I, p. 232-33) beschriebene Formen ( $P$. chierchiae, rivilli, punctata, americana, japonica), die ebenda beschrieben $P$. mollis dürfte einzuziehen sein; weiter $P$. (Cypridina) punctata Brady (nec Dana) und P. (Eupathistoma) natans (Brady), (1898, p. 437).

Die Unterscheidung der Arten bereitet bei der grossen Ähnlichkeit einige Schwierigkeit. Folgende Organe scheinen besondere Bericksichtigung zu verdienen: I) die Furca, im besonderen die Verschmelzung einzelner Dornen mit dem Stamm und die Grösse des 3 Dornes, 2) der rudimentäre Innenast der 2 Antn. und 3) die Schale. An letzterer ausser der Form die Behaarung des Vorderrandes und des Vorderendes an der medialen Seite. Bei zahlreichen Cypridininae (ursprünglich wohl bei allen Cypridiniden) trägt die mediale Seite proximal vom Saum eine dem Rand parallele Reihe von Borsten, deren Ursprung durch eine Leiste verbunden ist. Diese Reihe ist durch die Rostralincisur unterbrochen, kann sich aber ohne wesentliche Veränderung auf das Rostrum fortsetzen (vergl. Taf. 6, Fig. 6, Taf. 3, Fig. I 8 L), meist ist allerdings hier die Regelmässigkeit arg gestört. Nach hinten lässt sich die Leiste gewöhnlich bis zum hinteren Körperende verfolgen, doch hört sie meist in der hinteren Hälfte auf, Borsten zu tragen. Am hinteren Körperende biegt sie bei Pyrocypris (und anderen Formen) plötzlich dorsalwärts um, so dass der hintere Fortsatz ausserhalb (distal von) dieser Leiste liegt. In der Nachbarschaft des Fortsatzes ist die Leiste oft mit Spitzen besetzt, bald beiderseits, bald nur einseitig; der Raum zwischen Leiste und Schalenrand kann hier undeutliche Warzen oder deutliche Spitzen tragen (Taf. 3, Fig. 2, 3, I 4, I 5) oder einer bemerkbaren Skulptur entbehren, Verhältnisse, welche für die Unterscheidung der Arten von Wichtigkeit. Nicht immer trägt die genannte Leiste vorn Borsten, dieselben können vollständig fehlen. Ferner finden sich Borsten am Schalenrand, ihre Existenz ist unabhängig von der der erst beschriebenen Borstenreihe (bei Pyrocypris scheinen sie sich allerdings auszuschliessen).

I) Ich halte Cypridina punctatc Brady (1898, p. 89) nicht für identisch mit C. punctata Dana (1852, p. I293). Zudem war 1852 der Name C. punctata schon vergeben (Reuss 1849). BRADY's Art gehört augenscheinlich zu Pyrocypris, was bei DaNA's Art zweifelhaft. Da aber Pyrocypris punctata ebenfalls vergeben (G. W. MüLLER I89r), müsste der Namen geändert werden. Da sich BRADY's Darstellung anscheinend auf eine Larve bezieht, wäre die Art überhaupt einzuziehen. 
Alle von der Siboga gesammelten Vertreter der Gattung sind freischwimmend an Stellen mit geringer Tiefe ${ }^{1}$ ) gefischt, was gut zu der an anderem Ort (G. W. MüLler, I901, p. 2I3) ausgesprochenen Ansicht passt, dass die Formen den Grund bewohnen, nur gelegentlich zur Oberfläche aufsteigen.

Die früher (G. W. Müllen, I89I, p. 232) beschriebenen Arten waren meist in grösserer Entfernung vom Land und über beträchtlichen Tiefen gefischt.

Die hier beschriebene Arten lassen sich auf 3 kleinere natüliche Gruppen vertheilen:

I. $P$. acuminata;

2. 'P. sinuosa, inermis, dentata;

3. P. serrata, amphiacantha, lepidoptera.

Diesen Gruppen dürften sich auch die früher beschriebenen Arten einreihen lassen.

\section{Acuminata-Gruppe.}

Schalenrand unterhalb der Incisur mit einigen Borsten, mediale Seite ebenda ohne Borsten, alle Furcaldornen durch deutliche Naht vom Stamm abgetrennt, der 3. von normaler Grösse, so dass die Dornen gleichmässig an Grösse abnehmen.

I. Pyrocypris acuminata n. sp. Taf. 2, Fig. I-5.

Stat. 40. - 3 Indiv.

Stat. I I $7^{\mathrm{a}} \cdot-83$ Indiv.

Schale des $\sigma^{7}$ : Höhe wenig grösser als $1 / 2$ der Länge. Vordere Ecke des Rostrums stark abgerundet, fast ganz unterdrückt; ventrale spitzwinklig, hinterer Fortsatz ziemlich schmal, terminal winklig, die Ecke des Winkels meist deutlich, wenig abgerundet. Dorsal ist der Fortsatz wenig scharf abgegrenzt, er geht im flachen Bogen in den Dorsalrand der Schale über, an Stelle des flachen Bogens kann ein undeutlicher stumpfer Winkel treten. Der Saum häufig derart nach aussen gebogen, dass er die Incisur nicht ausfüllt (Fig. 4), doch kann er auch die gewöhnliche Lage haben, etwa wie in Taf. 2, Fig. 7. In der Incisur und ventral von ihr entspringen nahe dem Schalenrand oder auf demselben 2, resp. 3 oder 4 Borsten. Das Rostrum trägt auf seiner medialen Seite auf der Kante oder in deren Nachbarschaft etwa 6 Borsten; übrigens trägt die Leiste, welche nahe dem Ventralrand verläuft, keine Borsten. Am Hinterrand ist sie rechts (Fig. 6) mit kräftigen Spitzen besetzt, ähnliche Spitzen finden sich auch an der medialen Seite des hinteren Fortsatzes, zwischen Leiste und Schalenrand, links sind die Spitzen der Leiste deutlich kleiner, sonst wie rechts. Beim $q$ ist die Rostralincisur etwas schmaler und tiefer, der Dorsalrand in seiner hinteren Hälfte etwas stärker gewölbt, in Folge dessen die Bucht dorsal vom hinteren Fortsaz weniger flach; das Auge kleiner, weiter nach vorn verschoben. Borsten des Innenastes der 2 Antn. (Fig. 2) ungewöhnlich lang, besonders die proximale. Die Furcaldornen nehmen gleichmässig an Länge und Dicke ab, alle, auch der 2., sind durch eine deutliche Naht vom Stamm abgegrenzt.

Länge des o $1,8-2 \mathrm{~mm}$, des $0^{\top} \mathrm{I}, 9-2, \mathrm{Imm}$.

1) Soweit Angaben über die Tiefe vorliegen. 
Die Art steht P. (Eupathistoma) natans Brady (I898, p. 437, Taf. 44, Fig. 21-26) nahe, unterscheidet sich von ih durch das an der vorderen Ecke stark abgerundete Rostrum.

\section{Sinuosa-Gruppe.}

Die Schale trägt ventral vom Rostrums auf dem Rand eine Reihe von etwa ro Haaren; an der Furca ist der 2. Dorn mit dem Stamm verschmolzen, der 3. meist schwächer als man nach seiner Stellung erwarten sollte, doch nicht so auffällig wie bei der Serrata-Gruppe. Der Sinuosa-Gruppe gehören von den hier beschriebenen an: $P$. sinuosa, inermis und dentata, ferner $P$. chierchiae, rivilli, punctata und amerikana G. W. Müller (1891, p. 232, 233). Von den genannten Arten würden sich die hier beschriebenen ausser durch andere Merkmale unterscheiden durch den Mangel der Pigmentirung der Gliedmaassen und Schale. Man kann an die Möglichkeit denken, dass das Pigment geschwunden, was ja bekanntlich vielfach bei der Conservirung, besonders bei längerer Aufbewahrung geschieht, doch spricht dagegen, dass das Pigment bei den von mir I89 I beschriebenen Formen sehr widerstandsfähig war, dass sich auch im Siboga-Material eine Larve einer Pyrocypris fand mit wohl erhaltenen Pigmentflecken, und dass schliesslich das Augenpigment im allgemeinen erhalten war. Danach glaube ich im Mangel des Pigments ein differentialdiagnostisch brauchbares Merkmal sehen zu dürfen.

2. Pyrocypris sinuosa n. sp. Taf. 2, Fig. I I-I 6 .

Stat. $40 .+7 \sigma^{7}$.

Schale des $\sigma^{7}$ : Höhe deutlich grösser als ${ }^{1} / 2$ der Länge. Vordere Ecke des Rostrums ziemlich stark abgerundet, ventrale deutlich, Incisur ziemlich klein, ventral von ihr I2- I 6 Borsten auf dem Schalenrand. Hinterer Fortsatz ziemlich breit, dorsal deutlich abgegrenzt, terminal gerundet, Ventralrand in der hinteren Hälfte sehr flach gewölbt. Das paarige Auge liegt deutlich vor halber Schalenlänge. Medial zeigt das Vorderende nur I oder 2 Börstchen an der Leiste des Rostrums, übrigens die Leiste borstenlos, am Hinterende rechts bogig ausgeschnitten, links glatt. Am (rudimentären) Innenast der 2 Antn. nehmen die 4 Borsten von vorn nach hinten an Länge $z u$, die letzte ist etwa $4 \times$ so lang wie die erste.

Die Furcaldornen nehmen annähernd gleichmässig an Umfang ab, bis auf den 3., der an Länge zwischen dem 2. und 4. steht, aber schlanker wie der 4. ist. Der 2. Dorn ist nicht durch eine Naht vom Stamm getrennt.

Länge des $\sigma^{7}$ I,4-I,6 mm., \& unbekannt.

3. Pyrocypris inermis n. sp. Taf. 2, Fig. 6-10.

Stat. 40. - I 9,5 \%"

Schale des $\sigma^{7}$ : Höhe deutlich grösser als $1 / 2$ der Länge. Vordere Ecke des Rostrums deutlich, wenig abgerundet, ventrale Ecke in eine deutliche Spitze ausgezogen, hinterer Fortsatz ziemlich schmal, terminal gerundet, der einspringende Winkel dorsal von ihm gerundet; Ventralrand flach gerundet, nahe dem Hinterende ein undeutlicher stumpfer Winkel (kann fehlen), ventral von der Incisur eine Reihe von etwa io Borsten auf dem Schalenrand, im Bereich dieser 
Borsten ist der Rand gezähnt, die Zähnelung wird nach hinten deutlicher, hört plötzlich und unvermittelt auf. An der medialen Fläche keine Borsten bis auf 2 oder 3 an der Spitze des Rostrums. Leiste deutlich, beiderseits am Hinterende glattrandig (sie war hier bei allen untersuchten Individuen stark verschmutzt, so dass ihre Form nicht genau zu erkennen war; sicher war sie nicht deutlich gezähnt oder mit Spitzen besetzt). Schale des $q$ ähnlich, Rostralincisur etwas tiefer und schmaler.

An der Furca nehmen die Dornen ziemlich gleichmässig an Länge und Umfang ab, der 3. wenig schwächer, als man nach seiner Stellung erwarten sollte, der 2. ohne Naht mit dem Stamm verbunden.

Länge des $\%$ I, 6, des $0^{7}$ I, $8 \mathrm{~mm}$.

4. Pyrocypris dentata n. sp. Taf. 2, Fig. I $7-2 \mathrm{I}$.

Stat. 40. - I क्, I $\sigma^{7}$.

Stat. 66. - I $0^{7}$.

$P$. sinuosa sehr ähnlich, durch folgende Merkmale unterschieden: Hinterer Fortsatz etwas stärker abgerundet, die Zähnelung des Ventralrandes ist näher der Incisur am deutlichsten, nur wenige Zähne überragen hier deutlich den Rand, weiter nach hinten rïckt die Zahnreihe ganz auf die mediale Seite des Schalenrandes, bleibt aber durch die Schale hindurch deutlich sichtbar (Fig. I9). Am Hinterende trägt die Leiste beiderseits eine Reihe schlanker aber deutlicher Spitzen; der Ursprung der Leiste ist als auffällige Linie sichtbar, welche einen nach hinten offenen Bogen bildet, sich weit vom Rand der Leiste entfernt (Fig. I 8).

Der Innenast der 2 Antn. war bei keinem der untersuchten Exemplare vollständig erhalten. Furca ähnlich wie bei $P$. sinuosa, die Dornen länger und schlanker, stärker gebogen.

Länge des $q \mathrm{I}, 8$, des $\sigma^{\top} 2,0-2, \mathrm{I} \mathrm{mm}$.

\section{Serrata-Gruppe.}

Schalenrand unterhalb der Incisur nicht behaart, Leiste der medialen Seite ebenda mit Haaren. An der Furca I oder mehrere Dornen mit dem Stamm verschmolzen, stets wenigstens der 2.; der 3. nicht stärker und länger als der 4., bisweilen schwächer, stets in der Reihe der Dornen deutlich zurücktretend.

Ausser den genannten Arten dürften dieser Gruppe nach angehoren Cypridina punctata Brady nec Dana (1898, p. 89, Taf. I6, Fig. 5-9) (juv.?) und P. japonica G. W. Müller (I89I, p. 233). Letztere unterscheidet sich durch die stark abgerundete vordere Ecke zur Genüge von den hier beschriebenen.

5. Pyrocypris serrata n. sp. Taf. 3, Fig. I-7.

Stat. 40. $-50^{7}$.

Stat. 99. - $37 \sigma^{7}$.

Stat. Iog. - I I O'.

Schale des $\sigma^{7}$ : Höhe etwa $1 / 2$ der Länge; vordere Ecke des Rostrums etwas abgerundet, Vorderrand flach eingebuchtet, ventrale Ecke nicht in eine Spitze ausgezogen. Hinterer Fortsatz 
breit, am Ende flach gerundet, die dorsale Bucht deutlich, winklig, die Spitze des Winkels wenig abgerundet. Der Schalenrand trägt keine Borsten, doch können einige von den an der medialen Schalenseite entspringenden den Schalenrand etwas überragen. Medial finden wir am Rostrum etwa Io Borsten, die z. Th. auf der Kante, z. Th. auf einer dem Schalenrand parallelen Linie stehen; im Grunde der Rostralincisur stehen nahe bei einander zwei Borsten, auf der Leiste vereinzelte Borsten.

Im Bereich des hinteren Fortsatzes ist die Leiste links mit einer Reihe deutlicher Spitzen besetzt, welche ventralwärts an Umfang abnehmen; rechts ist sie glatt, nur in der dorsalen Hälfte lassen sich sehr kleine Spitzen nachweisen. Beiderseits finden sich nahe dem Schalenrand einige kleine Spitzen, hinter der Leiste zerstreute undeutliche Wärzchen.

Am Innenast der 2. Antn. ist die vorletzte Borste deutlich länger wie die anderen.

Furcaldornen ziemlich kurz und kräftig. Der 3. deutlich schwächer (schlanker) und, am Vorderrand gemessen, kürzer als der 4. Der 2. und 3. Dorn nicht durch eine Naht vom Stamm getrennt, zwischen den genannten Dornen der Stamm etwas verlängert (oder anders ausgedrückt, die beiden Dornen an ihrer Basis für ein kurzes Stück verschmolzen).

Länge des $\sigma^{7}$ r,9-2 mm., \& unbekannt (vergl. P. lepidophora, Schluss der Beschreibung).

6. Pyrocypris amphiacantha n. sp. Taf, 3, Fig. 8- 12.

Stat. I6. -2 б'.

$P$. serrata sehr ähnlich, von dieser Art durch folgende Merkmale unterschieden: Leiste am Hinterende beiderseits glatt, nicht in Spitzen ausgezogen; die mediale Seite des hinteren Fortsatzes annähernd glatt, keine deutlichen Warzen oder Spitzen; am Rand des Fortsatzes, auf seine dorsale Hälfte beschränkt, undeutliche bogige Linien; ähnliche Linien finden sich am Vorderende, sie haben nichts mit der Verwachsungslinie zu thun.

An der Furca ist der 3. Dorn durch eine deutliche Naht vom Stamm getrennt.

Länge des $\sigma^{\top}$ r,5-1,6 mm., o unbekannt.

7. Pyrocypris lepidophora n. sp. Taf. 3, Fig. I 3-23.

Stat. 40. - 5 q.

Stat. 99. - 9 , I I juv.

Schale des q: Höhe deutlich grösser als $1 / 2$ der Länge, Dorsal- und Ventralrand annähernd gleich stark gewölbt, bemerkenswerth erscheint die Wölbung des Ventralrandes in der hinteren Schalenhälfte, da sich die Art durch sie von allen bekannten Arten der Gattung unterscheidet. Vordere Ecke des Rostrums stark abgerundet, ventrale deutlich, nicht in eine Spitze ausgezogen. Incisur klein. Hinterer Fortsatz klein, undeutlich zugespitzt, die dorsale Bucht deutlich. Am Vorder- und Hinterende zeigt die Schale eine ziemlich deutliche schuppenartige Skulptur; dieselbe beschränkt sich auf eine schmale Randpartie an beiden Enden, scheint übrigens ganz zu fehlen. Das Rostrum zeigt an seiner medialen Seite eine ziemlich starke und dichte Behaarung, eine ziemlich dichte, etwas unregelmässige Reihe dem Rand etwa parallel, proximal von dieser zerstreute Borsten, unterhalb der Incisur trägt die Leiste auch ziemlich dicht stehende Borsten, nach hinten werden diese Borsten immer seltner, verschwinden in der hinteren Hälfte ganz. 
Der Schalenrand trägt keine Borsten. (Bei der Untersuchung dieser Verhältnisse, besonders am Ventralrand ist zu beruicksichtigen, dass sich beide Schalen etwas verschieden verhalten, ferner die perspectivische Verkürzung, welche die Borsten der Leiste, wenn sie stark medialwärts gerichtet sind, leicht übersehen lässt. Schliesslich scheint in der Lage von Leiste und Verschmelzungslinie eine ziemliche Variabilität zu herrschen).

Am Hinterrand ist die Leiste rechts mit starken Spitzen besetzt, links glatt, oder mit sehr kleinen Spitzen; zwischen Leiste und Rand finden sich beiderseits dicht stehende ziemlich deutliche Warzen, dieselben lassen einen breiten Randstreifen frei, auf dem sich eine einfache Reihe von etwa 6 deutlichen conischen Spitzen findet, links kann man bei einzelnen dieser Warzen in Zweifel sein, ob sie auf der Leiste oder neben derselben stehen.

Das 2. Glied der I Antn. zeigt an seinem Ventralrand deutliche Gruppen von Börstchen, die den Rand gesägt erscheinen lassen. Der Innenast der 2 Antn. des $q$ mit 5 (irrthümlich nur 4 gezeichnet) Borsten, von denen die 4. die längste; die 5. kommt ihr am nächsten, die I-3 deutlich kürzer als die 5. Furca mit ziemlich kurzen und kräftigen Dornen, der 3 etwa ebenso lang wie der 4, an der Basis wenig schwächer wie dieser. Der 5-9 Dorn conisch, nicht gebogen, der 2 und 4 mit dem Stamm verschmolzen, der 3 deutlich getrennt.

Länge des o I,7-1,9 mm., ठ unbekannt.

Während wir sonst die $\sigma^{\top}$ in der Überzahl finden oder die $q$ ganz fehlen, vermissen wir hier die $\sigma^{7}$. Umgekehrt vermissen wir bei $P$. serrata die $q$, und da sich beide Formen in Stat. 99 und 140 in grösserer Anzahl neben einander fanden, liegt der Verdacht nahe, dass sie als die Geschlechter einer Art zusammengehören. Immerhin unterscheiden sich beide Formen in so zahlreichen Merkmalen, auf welche sich sonst die secundären Geschlechtsmerkmale nicht zu erstrecken pflegen (vergl. Taf. 3, Fig. I -7 und I 3-23), dass ich mich nicht habe entschliessen können, beide in einer Art zu vereinigen, doch wird man bei weiteren Fängen die Frage der Zusammengehörigkeit im Auge behalten müssen.

Die Art hat Ähnlichkeit mit Cypridina punctata Brady (nec Dana) (BRaDY, I 898, p. 89, Taf. I6, Fig. 5-9), würde sich von dieser unterscheiden durch den stärker gewölbten Ventralrand, durch die Form der Furca (bei punctata der 2-4 Dorn mit dem Stamm verschmolzen) sowie durch die Grösse (punctata nur I,5 mm.). Vermuthlich ist Cypridina punctata eine Larve; dafür würde der Umstand sprechen, dass nur 8 Furcaldornen gezeichnet sind; in diesem Falt wäre sie vielleicht als Larve von $P$. lepidophora anzusprechen.

\section{Codonocera Brady.}

I873. Cypridina (pr. prt.) Claus, I873, p. 2 I 2.

-1902. Codonocera Brady I902, p. I88.

Schale derb, stark verkalkt, Rostrum stets ohne vordere Ecke, aber mit deutlicher ventraler Spitze, Incisur klein, aber deutlich. Hinterer Fortsatz meist deutlich. Beim $\delta$ ist der Dorsalrand annähernd gerade oder schwach gebogen, gegen den Hinterrand deutlich, meist in einer scharfen Ecke abgegrenzt. Der Dorsalrand der linken Schale bildet nahe dem Vorderende eine deutliche, meist sehr auffällige Ecke, die rechts fehlt. Schale des $q$ auffällig verschieden von der des $\sigma^{7}$, Dorsalrand meist deutlich gewölbt, gegen den Hinterrand meist nicht abgegrenzt, 
die Ecke in der vorderen Hälfte des Dorsalrandes schwach, undeutlich, oder ganz unterdrükt. Oberfläche in beiden Geschlechtern mit feiner aber scharf ausgeprägter fischschuppenartiger Skulptur (Taf. 8, Fig. 8), mit sternförmigen mehr oder weniger reich verzweigten Pigmentzellen von blauschwarzer Farbe (Taf. 8, Fig. I, 9); ähnliche Pigmentzellen finden sich auch im Körper, besonders in den Gliedmaassen. Zahl und Grösse der Pigmentzellen unterliegen innerhalb einer Art grossen Schwankungen, und wenn auch manche Arten durchweg reicher pigmentirt sind als andere, so eignen sich diese Merkmale wegen ihrer Variabilität innerhalb der einzelnen Art nicht zur Unterscheidung der Arten. Schale behaart, die Behaarung meist nur am Hinterrand leicht nachweisbar.

I Antn. des $0^{\pi}$ mit 2 sehr langen Borsten (etwa doppelte Länge der Gliederreihe), an den Männchenborsten fehlt die basale Saugscheibe (vergl. Taf. 6, Fig. 9 von Cypridina asymmetrica und Taf. 6, Fig. I3-I5 von Codonocera), nur ein Zweig trägt kleine Saugscheiben, aber nicht in einer Reihe angeordnet, sondern nach Art einer Dolde. Die Borste zeigt eine Anschwellung, dieselbe liegt distal vom I. Zweig (bei Cypridina proximal). Beim $q$ sind die längsten Borsten wesentlich kürzer, die längste etwa $\mathrm{I}^{1} / 2$ mal so lang wie die Gliederreihe.

Der Innenast der 2 Antn. des $\sigma^{7}$ ist als Greiforgan entwickelt, dreigliedig; das zweite Glied ist an seiner Basis schmal, distalwärts stark erweitert, terminal schräg abgestutzt, an der einen (in der Ruhelage) ventralen Ecke trägt es zwei grobgefiederte Borsten und eine Gruppe von meist 3 Warzen, an der anderen dorsalen Ecke lenkt sich das terminale Glied ein. Dieses ist bogenförmig gekrümmt, es besteht aus einem erweiterten Basalstuick und einem schlankeren Endstück, das Basalstück trägt eine Borste, über seine äussere (in der Ruhelage hintere) Fläche ziehen Leisten oder Rippen, die es im Profil gezähnt oder gewellt erscheinen lassen; diese Rippen können sich aus Zähnchen zusammensetzen, sie können sich weniger deutlich auch auf dem schlanken Endstück finden (Taf. 7, Fig. 5, 6, 21, 22). Die Spitze endet bisweilen zweitheilig (Taf. 9, Fig. 14); ich vermuthe, dass wir stets zwei Spitzen finden, dass sich eine derselben aber leicht der Beobachtung entzieht. Der Innenast des $q$ ist gestreckt, undeutlich dreigliedrig, das letzte Glied mit langer, terminaler Borste, die nicht immer scharf gegen das Glied abgegrenzt ist (Taf. 8, Fig. 7). In beiden Geschlechtern trägt das Basalglied der 2 Antn. neben dem Ursprung des Aussenastes eine Borste.

Mandibel, Maxille und Maxillarfuss (I Thoraxbein) wie bei Cypridina, die terminalen Klauen des Mandibulartasters ungewöhnlich lang und schlank. (BRADy sagt 1.c. p. x 88: "mouth organs as in Philomedes"; ich vermag nicht einzusehen, in welchen Charakteren eine Ubereinstimmung mit Philomedes existiren soll, sicher nicht in den Organen der O', die bei Philomedes zurückgebildet, bei Codonocera wohl entwickelt, aber auch in keiner Weise in denen der q). Am 2. Thoracalbein sind die 3 basalen Glieder vollständig mit einander verschmolzen, lassen keine Andeutung einer Trennung erkennen, nur das terminale ist deutlich abgegrenzt (Taf. 8, Fig. Io); es trägt zahlreiche Borsten, die unter einander ähnlich gestaltet, die der hinteren Ecke nicht durch Dicke ausgezeichnet.

Putsfuss (Taf. 7, Fig. 7) ohne deutlich abgesetztes. Entstiuck, mit langer Spitze, welche einen Kamm von etwa 6 langen Zähnen trägt, von denen der terminale der längste; an der Basis dieses Kammes steht ein umfangreicher, beweglicher(?) Chitinzahn. Borsten finden sich nur in 
geringer Anzahl, etwa Io. Furca (Taf. 8, Fig. 6) mit 4 Dornen, die gleichmässig an Länge und Umfang abnehmen. Oberlippe (vergl. Taf. 7, Fig. 8) mit 3 breiten, flachen Warzen und 4 (2 Paaren) kleinen fingerartigen Fortsätzen, die am hinteren Rand annähernd in einer Linie stehen. Auge und Frontalorgan in beiden Geschlechtern wohl entwickelt, von der gewöhnlichen Form.

Man wird die Vertreter der Gattung im allgemeinen leicht am Habitus erkennen, schon die Art der Pigmentirung erscheint charakteristisch. Im Bau der Gliedmaassen sind die Männchenborsten der I Antn. und der Innenast der 2. Antn. des $\sigma^{7}$ sehr characteristisch, aber auch das 2. Thoraxbein, Furca, Putsfuss und Oberlippe liefern gute Merkmale.

Die Unterscheidung der Arten bereitet einige Schwierigkeiten, Arten wie C. weberi, cruenta, polygonia und penicillum wird man zunächst geneigt sein, als einer Art angehörig anzusprechen, doch findet man bei genauerem Zusehen constante Unterschiede. Immerhin ist die Gefahr gross, das man Arten übersieht, zumal wenn ein Material von einiger hundert Individuen vorliegt, von denen man nicht jedes öfnen kann. Besondere Schwierigkeiten bereitet das Auffinden der als $\sigma^{7}$ und $q$ zusammengehörigen Formen, da beide Geschlechter durchweg sehr verschieden. Ich habe mich in erster Linie leiten lassen durch das Vorkommen in demselben Fang, weiter durch Grösse und Form. Bei der Untersuchung muss man sich sehr hüten, Larven als $q$ anzusprechen; man erkennt die geschlechtsreifen $q$ am Vorhandensein des stets gefüllten Receptaculum seminis, dasselbe ist leicht aufzufinden.

Von früher beschriebenen Cypridiniden gehören dieser Gattung an: Cypridina formosa Dana (I852, p. I296, Taf. 9I, Fig. 5). Die Darstellung bezieht sich auf ein 오, vielleicht von. C. weberi; eine sichere Identifizirung ist nicht möglich.

Cypridina stellifera Claus (1873, p. 2 I 2, Taf. I0), die Darstellung bezieht sich unzweifelhaft auf wenigstens 2 Arten, die Mehrzahl der Figuren wohl auf die auch hier als stellifera bezeichnete Art, Fig. I' und 2' auf ein oder zwei andere Arten, I' vielleicht auf 'C. polygonia.

BRADY (I9O2, p. I88) hat nur ein Individuum vorgelegen, wodurch er gegen ein Vermengung verschiedener Arten gesichert war; die Identificirung mit der hier unter dem Namen C. cruenta beschriebenen Art scheint mir genügend sicher. Vielleicht gehört Brady's Cypridina insolita (1902, p. 184, Taf. 22, Fig. I I-14) ebenfalls zu Codonocera.

Alle bisher gesammelten Vertreter der Gattung stammen aus dem malayschen Archipel, sie sind, so weit bekannt, pelagisch (Ausnahme? $\sigma^{\text {T }}$ von $C$. weberi aus Stat. IO4) in der Nähe der Küste an wenig tiefen Stellen gefischt, danàch dürften sie den Grund bewohnen, gelegentlich zur Oberfläche aufsteigen.

I. Codonocera weberi n. sp. Taf. 8, Fig. 7-9. Taf. 9, Fig. I-6.

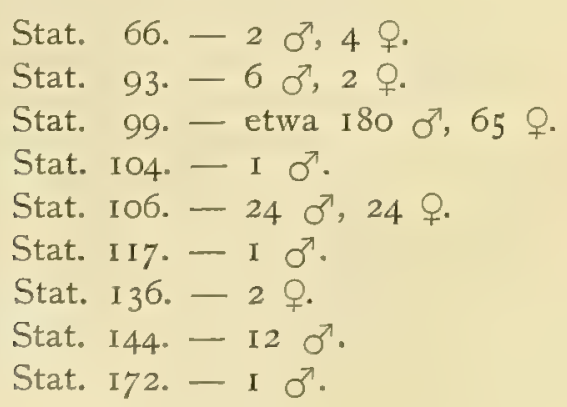


Schale des $\sigma^{7}$ : Höhe etwa $2 / 3$ der Länge. Links bildet der Dorsalrand auf etwa $1 / 6$ der Gesammtlänge der Schale eine deutliche, wenig abgerundete, stumpfwinklige Ecke, vor der er steil zum Rostrum abfällt, rechts ist diese Ecke abgerundet. Der Hinterrand bildet beiderseits mit dem Dorsalrand einen Winkel von etwa $90^{\circ}$ mit etwas abgerundeter Ecke, Hinterrand flach gewölbt, fast gerade, gegen den hinteren Fortsatz durch eine sehr flache Bucht abgegrenzt. Diese Bucht liegt beiderseits etwa auf $5 / 8$ der Höhe. Hinterer Fortsatz beiderseits deutlich, breit, an der Spitze gerundet. Ventralrand stark gewölbt. Meist reichlich und lebhaft pigmentirt.

Schale des $q$ : Höhe etwa $\%$ der Länge. Dorsalrand beiderseits flach gewölbt, ohne Andeutung einer Ecke in der vorderen Hälfte oder als Abgrenzung gegen den Hinterrand; Hinterrand steil abfallend, flach gewölbt, gegen den hinteren Fortsatz auf etwa 1/3 der Höhe durch eine flache Bucht deutlich abgegrenzt, hinterer Fortsatz beiderseits wenig umfangreich, aber deutlich, abgerundet; Ventralrand stark gewölbt.

Basalglied der I Antn. beiderseits ohne Dorn. Das terminale Glied des Greiforgans des o' bildet am Ursprung der Borste eine deutliche Ecke. Der Bogen, den das schlanke Endstück bildet, etwas eingedrückt, die Spitze etwas in die Höhe gerichtet, so dass es schwach doppelt $S$-förmig gekrümmt erscheint.

Länge des $q$ 2,65-3 mm., des $\sigma^{7} 2,2-2,6 \mathrm{~mm}$.

Die Zusammengehörigkeit von $\sigma^{7}$ und $q$ scheint mir durch das Vorkommen neben einander in grosser Zahl gesichert.

2. Codonocera penicillum n. sp. Taf. 9, Fig. 15-19.

Stat. 66. - I $0^{7}$.

Stat. I38. -2 \%".

Schale des $\sigma^{7}$ der von $C$. weberi $\sigma^{7}$ sehr ähnlich, von dièser dadurch unterschieden, dass der hintere Fortsatz schmaler und etwas stärker zugespitzt; o unbekannt.

Greiforgan des $\sigma^{7}$ : das Endglied ohne deutlich Ecke am Ursprung. der Borste, das schlanke Endstück einfach, nicht S-förmig gebogen. Die Höcker am Rande des Gliedes setzten sich als Reihen von Wärzchen oder Zähnchen auf die Fläche des Endgliedes fort; solche Reihen von Wärzchen finden sich auch schwach entwickelt auf dem schlankeren Endstück, wo sie im Profil nicht oder nur wenig deutlich hervortreten. Borste des letzten Gliedes lang, etwa so lang wie der dorsale (gerade) Rand des 2 Gliedes.

Erstes Glied der I Antn. mit deutlicher Spitze am Vorderrand.

Länge des $\sigma^{7}$ 2,2 mm.; \& unbekannt.

3. Codonocera cruenta Brady. Taf. 8, Fig. I-6, 10. Taf. 9, Fig. 7, 8.

1902. Codonocera cruenta Brady, 1902, S. 188, Taf. 22, fig. I-10.

Stat. 96. -4 o?.

Stat. 99. - I ठ

Stat. 106. $-4 \sigma^{7}$, 6 ㅇ.

Brady's Exemplar stammte von Pulo Penang.

SIBOGA-EXPEDITIE XXX. 
Schale des $\sigma^{\gamma}$ der von $C$. weberi $\sigma^{\top}$ sehr ähnlich, von ihr besonders unterschieden durch die viel stärkere Abrundung der hinteren dorsalen Ecke und die stärkere Wölbung des Hinterrandes dorsal vom hinteren Fortsatz.

Schale des $q$ der von $C$. weberi $q$ sehr ähnlich, der hintere Fortsatz etwas breiter, hinten quer abgestutzt, so dass er zwei meist deutliche Ecken bildet, die ganze Schale deutlich grösser.

Basalglied der I Antn. in beiden Geschlechtern ohne Dorn; Greiforgan des $\sigma^{7}$ : das terminale Glied ohne deutliche Ecke am Ursprung der Borste, das schlanke Endstück einfach $S$-förmig gebogen.

Länge des $ᄋ$ 3, I $5-3,4$, des $\sigma^{7} 2,7-3 \mathrm{~mm}$.

Für die Zusammengehörigkeit von $\sigma^{7}$ und $q$ spricht das wiederholte Vorkommen in demselben Fang, ferner die Ähnlichkeit mit $C$. weberi in beiden Geschlechtern, im besonderen auch das annähernd gleiche Grössenverhältniss beider Geschlechter.

4. Codonocera polygonia n. sp. Taf. 9, Fig. 9-I4.

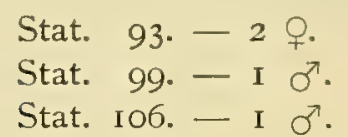

Schale des $\sigma^{7}$ der von $C$. weberi ơ ähnlich, unterschieden in folgenden Punkten: Hinterrand und Dorsalrand bilden mit einander einen deutlichen stumpfen Winkel, dessen Spitze nur wenig abgerundet ist; Hinterrand links schwach, rechts deutlich S-förmig geschwungen. Hinterer Fortsatz deutlich, weniger umfangreich als bei $C$. weberi, aber dorsalwärts deutlich abgegrenzt. Ventralrand in der vorderen Hälfte schwach aber deutlich eingebuchtet.

Linke Schale des $q$ (Zugehörigkeit? vergl. unten): Höhe ungefähr $5 / 7$ der Länge, der Dorsalrand schwach und unregelmässig gewölbt, auf etwa $1 / 5$ der Länge mit wenig auffälliger stumpfwinkliger Ecke. Dorsal- und Hinterrand bilden mit einander eine deutliche, wenig abgerundete, stumpfwinklige Ecke; Hinterrand steil abfallend, deutlich winklig gebogen, hinterer Fortsatz schmal aber deutlich, dorsalwärts scharf abgegrenzt. Ventralrand mässig stark gewölbt. Rechte Schale ähnlich, die vordere Ecke des Dorsalrandes unterdrückt.

I. Glied der I Antn. in beiden Geschlechtern ohne Dorn. Männchenborste kürzer und stärker aufgetrieben als gewöhnlich, mit etwa 6 ungewöhnlich grossen Saugscheiben.

2. Glied des Greiforgans des $0^{7}$ mit sehr kurzem, schlankem Basalstück, sehr plötzlich erweitert. Endglied am Ursprung der Borste deutlich eckig, das schlanke Endstück nur ganz schwach S-förmig gebogen.

Länge des $\sigma^{7} 2,25$, des $\uparrow 2,5 \mathrm{~mm}$.

Für die Zusammengehörigkeit der beiden hier als $\sigma^{7}$ und $q$ beschriebenen Formen scheint mir besonders die ähnliche Gestaltung des Hinterendes zu sprechen, bei beiden Formen grenzt sich der Hinterrand deutlich stumpfwinklig gegen den Dorsalrand ab, bei beiden ist er stumpfwinklig gebogen, bei beiden ist der hintere Fortsatz ziemlich schmal, abẹr deutlich. Auch das Grössenverhaltnisse würde passen. Immerhin ist es sehr wohl möglich, dass beide Formen nicht zusammen gehören. Wie aus den Fundortsverzeichniss ersichtlich, stammen sie nicht aus demselben Fang 
5. Codonocera pusilla n. sp. Taf 7, fig. 14-20.

Stat. 40. $-7 \sigma^{7}$ etwa 60 q.

Linke Schale des $\sigma^{7}$ : Höhe etwas über $3 / 5$ der Länge. Der annähernd gerade Dorsalrand bildet auf $1 / 5$ der Länge eine deutliche Ecke, vor der er steil unter etwa $45^{\circ}$ nach vorn abfällt; eine viel weniger deutliche, stark abgerundete Eck findet sich etwas hinter $\%$ der Länge, von ihr aus fällt der Hinterrand annähernd gerade bis zur dorsalen Grenze des hinteren Fortsatzes $\mathrm{ab}$; hinterer Fortsatz klein, aber deutlich, dorsalwärts deutlich abgegrenzt, die Grenze liegt wenig über $1 / 2$ der Höhe. Ventralrand stark gewölbt. Rechte Schale ähnlich, die vordere Ecke des Dorsalrandes liegt weiter nach hinten, ist stark abgerundet, undeutlich, die hintere ganz unterdrückt.

Schale des $q$ der von $C$. weberi $q$ ähnlich. Vorderrand des I Gliedes der I Antn. beim $\sigma$ ohne Dorn, beim o meist mit umfangreichem Dorn (kann fehlen); Männchenborste mit nur 4-6 Saugnäpfen. Letztes Glied des Greiforgans des $\sigma^{7}$ ohne deutliche Ecke am Ursprung der Borste, die Leisten undeutlich gezähnt, das schlanke Endstück ziemlich stark aber nicht $S$-förmig gebogen.

Länge des $\sigma^{7} \mathrm{I}, 8-\mathrm{I}, 9$, des ๆ $\mathrm{I}, 9-2,0 \mathrm{~mm}$.

$\mathrm{Da}$ die hier als $\sigma^{\top}$ und $q$ einer Art beschriebenen Formen annähernd in der Grösse übereinstimmen, sich ferner in einem Fang fanden, kann an ihrer Zusammengehörigkeit kaum ein Zweifel existiren. Bemerkenswerth erscheint das Überwiegen der $q$ in dem Fang.

6. Codonocera stellifera Claus. Taf, 6, Fig. 13-i6. Taf. 7, Fig. I-9.

1872. Cypridina stellifera (pr. prt.) Claus, I873, S. 212, Taf. IO; Taf. II, fig. I5, I6.

Stat. 66. - I 9 , I $\sigma^{7}$.

Stat. 93. -2 \%

Stat. 99. - I10 87, 16 \%.

Stat. 106. - I ठ7.

Stat. I09. - I O?.

Stat. I 29. -30 .

Stat. 136. -28 .

Die von Claus untersuchten Tiere stammten von der Insel Palawang.

Linke Schale des $\sigma^{7}$ : Höhe etwa $3 / 5$ der Länge, Dorsalrand gebogen oder geknickt, auf etwa $1 / 2$ der Länge liegt eine stumpfwinklige Ecke. Etwas vor $\%$ der Länge bildet der Dorsalrand eine zweite stumpfwinklige Ecke, vor der er nach vorn abfällt, die Ecke ist nicht so deutlich wie bei den bisher ( $\mathrm{I}-4$ ) beschriebenen Arten der Gattung. Eine hintere sehr deutliche stumpfwinklige Ecke von etwa $\mathrm{I} 35^{\circ}$ liegt auf $8 / 9$ der Schalenlänge. Der Hinterrand einfach gewölbt, die Wölbung bisweilen buckelartig vortretend, der hintere Fortsatz undeutlich, flach, nicht deutlich dorsalwärts abgegrenzt. Ventralrand ziemlich flach gewölbt, deutlich flacher als bei den bisher besprochenen Arten $(\mathrm{I}-5)$. Rechte Schale der linken ähnlich, die vordere Ecke ganz unterdrückt, die hintere ebenso deutlich wie links, der Hinterrand mit vortretender stumpfer mehr weniger stark abgerundeter Ecke an Stelle der Wölbung, bisweilen die Wölbung sehr flach.

Linke Schale des $q$ : Höhe etwa ${ }^{3} / 4$ der Länge, Dorsalrand ziemlich flach und unregelmässig 
gewölbt, gegen den Hinterrand durch eine stumpfwinklige aber meist deutliche Ecke abgegrenzt, Hinterrand stumpfwinklig gebogen, die Ecke abgerundet, hinterer Fortsatz flach, undeutlich.

Vorderrand des Basalgliedes der $\mathrm{r}$ Antn. in beiden Geschlechtern mit einem kleinen Zahn. Letztes Glied des Greiforgans des $\sigma^{\top}$ am Ursprung der Borste gerundet, ohne Andeutung einer Ecke; die Leisten unregelmässig gezähnt, das schlanke Endstück schwach, nicht S-förmig gebogen, die distale Hälfte fast gerade.

Länge des 우 3,0-3, 5 , des $\sigma^{7} 3,0-3,25 \mathrm{~mm}$.

Die Zusammengehörigkeit der hier als $\sigma^{7}$ und $q$ beschriebenen Formen kann kaum einem Zweifel unterliegen, zunächst finden sich beide Formen 2mal neben einander, das eine Mal (Stat. 99) in grösserer Anzahl; dann zeigen sie auch in einigen Charakteren (geringe Entwicklung des hinteren Fortsatzes, Biegung des Hinterrandes) deutliche Beziehungen. Bemerkenswert erscheint die geringere Grösse des $\$$; trotzdem halte ich, wie gesagt, die Zusammengehörigkeit für erwiesen.

7. Codonocera goniacantha n. sp. Taf. 7, Fig. IO-I3, 21, 22.

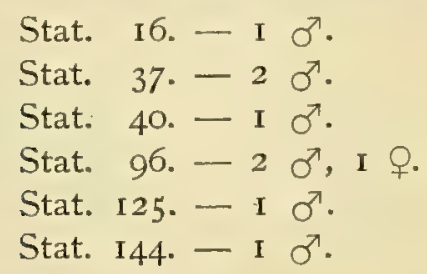

Schale des $\sigma^{7}$ der von $C$. stellifera. $\sigma^{7}$ ähnlich, links Dorsalrand annähernd gerade, vordere und hintere Ecke deutlicher, auch rechts die hintere Ecke deutlicher, kleiner. Schale des $q$ ebenfalls ähnlich der von $C$. stellifera 9 , links auf etwa $1 / 4$ des Dorsalrandes eine wenig ausgeprägte Ecke, der Hinterrand bildet beiderseits mit dem Dorsalrand eine deutliche, stumpfwinklige Ecke, er fällt steil, fast senkrecht ab, ist winklig geknickt, die Spitze des. Winkels wenig abgerundet. Hinterer Fortsatz breit, sehr undeutlich; eine dorsale Grenze kaum angedeutet.

Vorderrand der I Antn. beim $\sigma^{7}$ und $\circ$ mit kleinem Dorn oder ohne Dorn. Am Greiforgan des $\sigma^{7}$ ist das 2. Glied etwas stärker erweitert als bei $C$. stellifera, das Endglied dem von $C$. stellifera sehr ähnlich, etwas schlanker, die Zähnelung dẹr Rippen weniger deutlich.

Länge des $ᄋ$ 2,6, des $\sigma^{\top} 2,25-2,6 \mathrm{~mm}$.

Die Zusammengehörigkeit der hier als $\sigma^{7}$ und $q$ beschriebenen Formen scheint mir durch die Ähnlichkeit mit C. stellifera in beiden Geschlechtern zur Genüge sicher gestellt; auch fand sich das einzige $ᄋ$ neben $2 \sigma^{7}$.

\section{Crossophorus Brady.}

1880. Crossophorus G. S. Brady, I880, S. I57.

1906. Crossophorus G. W. Müller, 1906, S. 133 .

I. Crossophorus gibber n. sp. Taf. 4, Fig. I-9.

Stat. 2II. - I $0^{7}$.

Schale des $\sigma^{7}$ kurz oval, Höhe etwa $\%$ der Länge, Rostrum klein, ohne vordere, aber mit deutlicher ventraler Spitze, Rostralincisur klein, sie liegt etwa auf $1 / 2$ der Höhe, eher tiefer. 
I Antn. am 2-4 Glied nur dünn mit Borsten besetzt, das 2. Glied am dorsalen Rand mit etwa 8, am ventralen mit 2, das 3 Glied mit 5 resp. I, das 4 Glied mit 2 resp. 4 Borsten. Von den Borsten des letzten und vorletzten Gliedes sind die 4 längsten ziemlich reich verzweigt, reicher als bei der Mehrzahl der Vertreter der Gattung, die Seitenzweige zweier Borsten des letzten Gliedes sind zum grösseren Theil am Ende schwach kolbig erweitert, die Erweiterung ist zartwandig (Riechborsten?), zwischen derartig erweiterten Borsten können sich einfach spitze finden, können mit diesen abwechseln, doch überwiegen die kolbig erweiterten stark (Fig. 8). Die Seitenzweige der anderen Borsten, wie auch die der Sinnesborste des 5 Gliedes zeigen das gewöhnliche Aussehen. Haftorgane (Saugscheiben) fehlen.

Innenast der 2 Antn. des $\sigma^{7}$ wohl entwickelt, deutlich dreigliedrig, das letzte Glied schlank, stark gebogen, einschlagbar, es trägt nahe seiner Basis eine Borste, die annähernd so lang wie die beiden basalen Glieder.

2 Thoraxbein mit kurzem, am Ventralrand deutlich abgesetztem, terminal gerundetem Zipfel an der hinteren Ecke des terminalen Gliedes; der Hinterrand des genannten Gliedes trägt nahe seiner ventralen Ecke einige längere Borsten, über diesen ist er kahl.

Der Putsfuss trägt terminal auf kurzem Höcker 5 schlanke, fingerartige Fortsätze, diesem handartigen Gebilde steht keine Spitze gegenüber. Übrigens trägt der Putsfuss ziemlich zahlreiche (etwa 60) typische gegliederte Borsten. (Beide Putsfüsse des untersuchten Individuums waren in einer Kalkconcretion eingehuillt; nach Auflösung derselben gelang es die oben wiedergegebenen Details festzustellen, doch war es nicht möglich ein brauchbares Bild des ganzen Putsfusses oder des distalen Abschnittes zu geben).

An der Furca sondern sich, wie bei den anderen Vertretern der Gattung, die Dornen in kräftigere Haupt- und schwächere Nebendornen, die letzteren sind viel schlanker, aber nicht oder nur wenig kürzer als die benachbarten Hauptdornen; sie stehen wenig mehr lateral, sind etwas lateral gerichtet, etwas schwächer bewehrt als die Hauptdornen. Hauptdornen sind der I, 2, 5, 7, 9, I I, Nebendornen der 3, 4, 6, 8, IO; die auf den I 1. Dorn folgenden 8 Dornen nehmen allmählich an Umfang ab, werden schliesslich borstenförmig, doch existiren hier keine deutlichen Gegensätze, welche eine Unterscheidung in Haupt- und Nebendornen berechtigt erscheinen liesse.

Frontalorgan sehr klein, nicht pigmentirt, seitliche Augen habe ich nicht aufzufinden vermocht. Länge des or $4 \mathrm{~mm}$.

Das einzige Individuum, das ich untersuchen konnte war ein $\sigma^{7}$, das von Stat. 2 I I stammte. (Grundbewohner).

Die Art is mit ihrer Länge von $4 \mathrm{~mm}$. bei weitem der kleinste Vertreter der Gattung; die anderen Vertreter erreichen 7,5- 15,5 mm. Sie dürte $C r$. imperialis Stebbing (1902, p. 79) = imperator Brady-Norman (1 896, p. 643, Taf. 53, Fig. I-I I) am nächsten stehen, unterscheidet sich von dieser Art besonders durch die Furca, durch die geringere Zahl der Furcaldornen. (Bei imperialis finden sich zwischen dem 3 und 4, 4 und 5 Hauptdorn je zwei Nebendornen, bei gibber nur einer). Doch scheint die Möglichkeit nicht ausgeschlossen, dass es sich hier lediglich um Altersunterschiede handelt. Sollte die Art nach erreichter Geschlechtsreife weiter wachsen, so wäre eine Vermehrung der Furcaldornen keineswegs unwahrscheinlich. Bei Cr. africanus fand 
ich Verschiedenheiten in der Zahl der Furcaldornen, die vielleicht mit dem Alter in Zusammenhang standen. Immerhin halte ich es für wahrscheinlicher, dass wir es mit einer neuen Art zu thun haben, auch mit Rücksicht auf die geographische Verbreitung. Von Cr. imperator unterscheidet sich die Art, ausser in anderen Merkmalen, durch die viel geringere Zahl der Borsten am 2-4, besonders am 3 und 4 Glied der I Antn., von Cr. africanus durch die Form des Putsfusses.

\section{SARSIELLinaE}

mit der einzigen Gattung

\section{Sarsiella Norman.}

I868. Sarsiella Norman, I868, S. 293.

I894. Sarsiella G. W. Müller, I894, S. 2 I3.

Von dieser interessanten Gattung fanden sich in dem Siboga-Material nur 2 Individuen, beides Larven, anscheinend verschiedenen Arten angehörig. Ich verzichte darauf, die Formen zu benennen, da man mit der Beschreibung von Larven in einer Gattung mit anscheinend recht zahlreichen, sicher aber sehr ähnlichen Arten nur Verwirrung stiftet. Die eine dieser Larven gehörte einem jungen $q$ an, das im Bau der Schale und Gliedmaassen Sarsiella capsula sehr nahe stand. Das andere Individuum spreche ich als junges $\sigma^{7}$ an, es beansprucht als solches einiges Interesse, weshalb ich es hier kurz beschreiben will ${ }^{1}$ ).

Um zu zeigen, inwiefern die Form von Interesse, muss ich mit wenigen Worten auf den Dimorphismus beider Geschlechter von Sarsiella eingehen (vergl. darüber G. W. MüLler, I 894 , S. 2I3). Die $q$ von Sarsiella zeichnen sich durch eine sehr sonderbare Schalenform aus, sie entbehren durchaus eines deutlichen Rostrums, die Schale hat oft annähernd die. Form eines Kreises, der am Hinterende einen kurzen Fortsatz trägt. Der Habitus ist ein so eigenthümlicher, dass man die Form, solange man nur die Schale kannte, provisorisch zu den Cytheriden stellte. Auch die Gliedmaassen weisen mancherlei Eigenthümlichkeiten auf, so besonders die Mandibel und Maxille.

Als of dieser Form sprach ich 1894 Tiere an, welche eine ganz andere Schalenform haben, die Schale ist mehr weniger gestreckt, hat ein deutliches Rostrum, verräth durch ihren Habitus sofort ihre Zugehörigkeit zur Familie der Cypridiniden. (Vergl. Taf. 4, Fig. Io). Die Gliedmaassen zeigen neben manchen auffalligen Beziehungen zu Sarsiella $\&$ (Gliederung der I Antn.) zahlreiche Besonderheiten, von denen in erster Linie die Rückbildung des Putsfusses bemerkenswerth erscheint. BRADY hatte (1890) für diese Formen die Gattung Streptoleberis aufgestellt, Bradx-Norman I 896 die Gattung Nematohamma, ich sprach sie, wie gesagt i 894 als die or von Sarsiella an, eine Ansicht der sich BRADy I 898 (p. 438) wenigstens für die Gattung Nematohammx ausdrücklich anschloss. Die Gründe für diese Ansicht sind 1.c. p. 2 I 4 zusammengestellt. Im Jahr 1902 hat T. ScotT (I902, p. 475) das angebliche or von Sarsiella capsula

I) Eine ähnliche Form hat BRADY (1902, S. 189, Taf. 23, Fig. 16-2I) als Sarsiella ornithoides von Ceylon beschrieben. Es handelt sich augenscheinlich ebenfalls um ein junges $\delta$. 
beschrieben. ScotT kennt augenscheinlich meine Auseinandersetzungen über den Dimorphismus bei Sarsiella nicht, sonst könnte er nicht sagen "No male of Sarsiella capsula appears to have been described hitherto". Auch macht er keinerlei Versuch, sich mit meinen Ansichten auseinanderzusetzen. Sein $\sigma^{7}$ zeigt fast durchgehends die Charaktere des $q$ bis auf den Innenast der 2 Antn., der aber auch nicht etwa als Greiforgan gestaltet ist, und den Aussenast, dessen Borsten in ganzem Umfang gefiedert sind. Augenscheinlich hat Scotr eine Larve eines or (von Sarsiella laevis?) vorgelegen, die in der Schalenform und im Bau der Gliedmaassen fast durchgehends die Charactere des $q$ zeigt (G. W. MüLler, I894, p. I87) oder wenigstens zeigen kann (vergl. unten).

Bei der folgenden Beschreibung beschränke ich mich darauf, auf die Übereinstimmung mit den betreffenden Organen der $q$ oder $\sigma^{7}$ hinzuweisen, verweise wegen deren Darstellung auf die citierte Beschreibung (G. W. MüLler, I 894, S. 2 I 3, 2 I4). Vergl. übrigens Taf. 4, Fig. Io-I8.

Die Schale (Fig. IO) ist gestreckt, hat ein deutliches Rostrum, sie hat durchaus nicht den Habitus einer Sarsiella o, wohl aber den einer Streptoleberis (Sarsiella ơ), sie misst 0,85 mm. Die I. Antn. (Fig. 18) hat den typischen Bau dieses Organes von Sarsiella of, von der grossen, sehr reich verzweigten Sinnesborste des 3 (5) Gliedes ist nichts zu sehen.

Der Aussenast der 2. Antn. (Fig. I 7 ) trägt lange, ungefiederte Borsten, die, wie beim O, in ihrer proximalen Hälfte in grossem Umfang mit Dörnchen bewehrt sind (nur bei einer Borste gezeichnet), der Innenast ist ungegliedert, aber ziemlich umfangreich, er lässt eine Entwicklung zu einem Greiforgan erwarten.

Die Mandibel (Fig. I I) gleicht in der Hauptsache der der $\sigma^{7}$; bemerkenswerth ist der kleine mundwärts gerichtete Fortsatz des Basalgliedes; bekanntlich finden wir einen ähnlichen Fortsatz bei anderen Cypridiniden sehr verbreitet, bei Sarsiella (auch den $\sigma^{7}$ ) schien er ganz zu fehlen. Die Maxille (Fig. I3, I4) ist kräftig, stark bedornt, zeigt den charakteristischen Bau der $q$ von Sarsiella (bei den $\sigma^{7}$ ist sie rudimentär). Das I Thoraxbein (sogen. 2. Maxille) (Fig. I 2) gleicht ebenfalls dem betreffenden Organ des q. Die nächste Gliedmaasse (2 Thoraxbein, Fig. I6), trägt ziemlich kräftige und kurze Borsten, ist kräftiger bewehrt als bei den ? und $\sigma^{7}$ von Sarsiella (soweit dies Organ bekannt, was nur bei zwei Arten der Fall); auch zeigt es deutliche Reste einer Gliederung, die wir bei Sarsiella vermissen; es hat die meiste Ähnlichkeit mit dem von Pseudophilomedes (G. W. Müller, I 894, Taf. 3, Fig. 50). Der Putzfuss (Fig. I $5, P_{3}$ ) ist winklig geknickt, kurz, ungegliedert (Form des $\sigma^{7}$ ). Furca (Fig. I5) mit 5 deutlichen Dornen, ihre Form passt zur Gattung Sarsiella. Über das paarige Auge und das Frontalorgan habe ich mir keine genaue Vorstellung bilden können. Die Anlage der äusseren Geschlechtsorgane besteht aus einem unpaaren Zapfen, vor dem sich 2 paarige finden.

Mit Rücksicht auf die Beschaffenheit des Innenastes der 2 Antn. und der Anlage der äusseren Geschlechtsorgane halte ich es für erwiesen, dass wir es mit einem jungen $\sigma^{7}$ zu thun haben. Überblicken wir die sämmtlichen Charaktere noch einmal, so zeigen einige Gliedmaassen eine sehr weit gehende Übereinstimmung mit denen der $q$ von Sarsiella, so die I Antn., die Maxille und das I Thoraxbein. Das sind Anhänge, welche bei Sarsiella $q$ einen sehr charakteristischen Bau aufweisen; auch die Furca und die 2 Antn. (umfangreiche Bedornung der Schwimmborsten) sind zu nennen. Danach kann es keinem Zweifel unterliegen, dass die Art in den 
Formenkreis der Gattung Sarsiella gehört, wenn es auch nicht ausgeschlossen erscheint, dass bei genauerer Kenntniss eine Abtrennung als Untergattung angebracht erscheinen würde (Bau des 2 Thoraxbeines). Nicht zu Sarsiella , wohl aber zu den praesumptiven ơ passt die Schalenform, die Mandibel und der Putzfuss. Weder zum $q$ oder $\sigma^{7}$ das 2 Thoraxbein." Zunächst sprechen wohl diese Thatsachen sehr entschieden für die Zusammengehörigkeit der von mir als $\$$ und $\sigma^{7}$ bezeichneten Formen. Die Verhältnisse liegen ähnlich wie bei Philomedes, auch dort haben wir weitgehende secundäre Geschlechtsmerkmale, die sich ausser auf Bewegung und Sinnesorgane auf Schalenform und Fresswerkzeuge beziehen, letztere sind beim ơ zurückgebildet. Alle Organe bewahren, von geringfügigen Annäherungen an die definitive Form abgesehen, beim $\sigma^{\Im}$ bis zur letzten Häutung die Form des 오. Bei Sarsiella liegen die Verhältnisse insofern etwas anders, als bereits frühseitig bei einigen Charakteren eine weitgehende. Annäherung an den definitiven Zustand des or eintritt, so im Bau des Putsfusses, im Bau der Mandibel und in der Schalenform, in den beiden letzten Charakteren allerdings nicht allgemein. Und hier kommen wir auf den interessantesten und schwierigsten Punkt aus der Entwicklungsgeschichte des $\sigma$ von Sarsiella.

Ich habe an anderem Ort (1894, p. I87) ein junges ot von Sarsiella kurz beschrieben, das in allen Charakteren, ausser dem Putsfuss, die Charaktere des $q$ zeigte, wir lernen hier ein junges of kennen, das sich auch in der Schalenform und im Bau der Mandibel von der Form des ㅇ entfernt, sich der definitiven Form des ơ nähert. Beruhen diese Differenzen auf Altersunterschieden, oder zeigen verschiedene Arten so auffällige Differenzen in der Entwicklung? Ich vermuthe das letztere, doch erscheint es müsig, sich auf Grund von 2 Larven in weitere Speculationen einzulassen. Doch möchte ich mit wenig Worten auf das allgemeinere Interesse hinweisen, das eine genauere Kenntniss der Entwicklung dieser Gattung zu bieten scheint. Das $\sigma^{7}$ bewahrt in der Schalenform unzweifelhaft ursprünglichere Verhältnisse als das $q$; wenn wir trotzdem, wenigstens bei einem Theil der Arten, die Form des $q$. der des $\sigma$ vorausgehen sehen, so herrscht hier in der Ontogenese eine Umkehrung der Phylogenese. Es wäre sehr erwünscht, wenn die Entwicklung von Sarsiella an einem reicheren Material klar gelegt würde. In den europäischen Meeren scheint die Gattung zu selten, als das hier Aussicht auf Erlangung des nöthigen Materials; in der Südsee scheint sie gelegentlich häufig vorzukommen (vergl. G. S. BradX, I 890 , S. 5I6).

\section{Cylindroleberinae.}

Diagnose vergl. die Diagnose der Gattung Cylindroleberis G. W. Müller, I894, S. 2 r6.

BRAdy hat (1898, p. 85) von Cylindroleberis (Asterope) die Gattung Cyclasterope abgetrennt. Auf Grund der Diagnose, die er 1. c. giebt, ist eine Trennung nicht durchführbar, die unterscheidenden Merkmale sind so unbestimmt, dass sie eben eine Unterscheidung nicht gestatten; ein Unterschied beruht auf falscher Beobachtung (Bau der: Mandibel). Trotzdem scheint eine Abgrenzung der sehr kurzen, annähernd kreisförmigen Arten, welche bei BRADV die Gattung Cyclasterope bilden, nicht unberechtigt. Dieselben charakterisiren sich scharf durch den Bau der Furca, bei der auf 3 oder 4 kurze, kräftige, stark gebogene Dornen, welche in grösserem 
Abstand von einander stehen, noch eine grössere Anzahl dicht stehender borstenartiger Gebilde, welche sich in ihrer Form scharf von den Dornen trennen, folgen. Bei dieser Charakteristik würde die Gattung Cyclasterope umfassen: Cyclasterope orbicularis Brady (I898, p. 87, Tab. I5, Fig. I3-I9), boulum Brady (1898, p. 432, Tab. 43, Fig. 24-30), tenera Brady (1898, p. 433, Tab. 44, Fig. 27-29; vermuthlich Larve), zealandica Baird (Brady I898, p. 433, Tab. 43, Fig. I 5-23), brevis G. W. Müller (1891, p. 239, Tab. 25, Fig. 10; Tab. 26, Fig. 7; Tab. 27, Fig. 7-IO, I5, I6) amerikana G. W. Müller (I89I, p. 240, Tab. 25, Fiğ. I6; Tab. 26, Fig. 9; Tab. 27, Fig. II), lobianci G. W. Müller (I894, p. 220, Tab. 4, Fig. 40, 42; Tab. 5, Fig. 2, 3, 26, 32, 34, 40). Unzweifelhaft nicht zu dieser Gattung gehören würde Cylindroleberis hilgendorfi G. W. Müller = Cyclasterope hendersoni Brady (Citate vergl. unten) und C. fascigera Brady (I902, p. 18I, Tab. 2I, Fig. 20-3I), sie passen zu ihr weder nach der Schalenform, noch nach dem Bau der Furca. Die Gattung Cylindroleberis s. str., der fast sämmtliche übrigen Arten angehören würden, würde sich charakterisiren durch den Besitz von

- wenigstens 5 unter einander ähnlich gestalteten Furcaldornen; dieselben sind schlank, stehen dicht (Zwischenraum kleiner als die Dornen an der Basis breit); ob nicht eine weitere Auflösung dieser Gattung berechtigt wäre, vermag ich zur Zeit nicht zu übersehen. Keinen Platz würde bei dieser Trennung finden Cylindroleberis fusca (G. W. Müller 189I, p. 242, Tab. 25, Fig. I I-I 3; Tab. 27, Fig. I9-22, 25). In der Differenzirung der Furcaldornen würde sie sich Cyclasterope, im Bau der Dornen Cylindroleberis s. str. anschliessen. Nach dem Bau der Schale nimmt sie unzweifelhaft eine ganz gesonderte Stellung in der Unterfamilie der Cylindroleberinae ein; bei einer Revision derselben müsste für diese Art eine besondere Gattung aufgestellt werden.

\section{Cylindroleberis.}

1840. Asterope Philippi, I840, S. I86-i 88 (nom. praeocc.).

1868. Cylindroleberis G. S. BRADY, I868, S. I27.

1894. Cylindroleberis (pr. prt.), G. W. Müller, I894, S. 216.

I. Cylindroleberis hilgendorfii (G. W. Müller). Taf. 5, Fig. I-5.

I89I. Asterope hilgendorfii G. W. Müller, I89I, S. 24I, Taf. 25 fig. I5; Taf. 26, fig. 8, 20;

Taf. 27 , fig. $4-6$, 17 .

I898. Cyclasterope hendersoni Brady, I897, S. 86, Taf. 15, fig. I-I2.

1900. Asterope arthuri Stebbing, 1900, p. 660, Taf. 72 A. (mas. juv.)

Stat. 6. -3 juv.

Stat. 51. - I ㅇ, 1 o $0^{\top}$.

Stat. IO4. - I 9.

Stat. 260. - I ㅇ. Alle Individuen sind vom Grund heraufgebracht.

Verbreitung: Pacifik (Küste von Japan und Bismarck-Archipel), Indik (Küste von Vorder-Indien).

Wegen der Darstellung des $q$ verweise ich auf die citirten Stellen, füge hier nur einige Angaben über das $\sigma^{7}$ hinzu. Die Schale des $\sigma^{7}$ ist, wie bei allen oder den weitaus meisten Vertretern der Gattung Cylindroleberis, viel gestreckter als die des $\%$, Höhe etwa ${ }^{7 / 10}$ der Länge 
(am ganzen Thier ist in Folge der stärkeren Krümmung des Dorsalrandes der linken Schale die Höhe grösser als in Fig. I, die nach einer isolirten rechten Schale gezeichnet ist). Dorsal- und Ventralrand deutlich und annähernd gleich stark gewölbt. Hinterende breit gerundet, ohne Andeutung eines Fortsatzes, Rostrum mit stark abgerundeter, fast ganz unterdrückter vorderer Ecke (links etwas deutlicher wie rechts), mit deutlicher ventraler Spitze. Incisur deutlich aber nicht tief, unterhalb der Incisur rechts (links?) ein flacher Wulst. Rundliche Gruben wie beim $ᄋ$, am Hinterende der für die $\sigma^{7}$ der Gattung charakteristische Haarkranz, derselbe ist sehr dicht. Die Sinnesborste der I Antenne mit ausserordentlich dichter Behaarung, zwei terminale Borsten, wie bei anderen Vertretern der Gattung und Familie, ausserordentlich verlängert, etwa $3 \times$ so lang wie die Gliederreihe. Am Innenast der 2 Antn. (Fig. 4, 5) ist das einschlagbare Endglied schlank, spitz, ziemlich stark gekrümmt, an der inneren, dem vorhergehenden Glied zugewandten Seite ist es scharfkantig gerieft. Das 2. Glied des Innenastes trägt nahe der Einlenkung des 3. eine Gruppe von etwa 8 Borsten. Putzfuss und Furca wie beim $\supsetneq$.

Länge des $q$ 6,25-8 mm. (nach den Angaben von Brady, Stebbingr und Müller), das $\sigma^{7}$ maass $5,4 \mathrm{~mm}$.

An der Zugehörigkeit der hier beschriebenen Form des $\sigma^{7} \mathrm{zu}$ Cylindroleberis hilgendorfii kann kaum ein Zweifel herrschen. Für dieselbe spricht in erster Linie die Übereinstimmung im Bau der Gliedmaassen, im Besonderen des Putsfusses und der Furca. Weiter muss zu einem $\sigma^{\prime}$ von über $5 \mathrm{~mm}$. Länge nothwendig ein $q$ von wenigstens $6 \mathrm{~mm}$. Länge gehören. Schliesslich fand sich das of zusammen mit einem of der Art.

2. Cylindroleberis australis (G. Brady)(?).

1890. Asterope australis G. S. Brady, I890, S. 515, Taf. 4, fig. I, 2.

I898. Asterope australis G. S. Brady, I898, S. 43I, Taf. 43, fig. I-8.

Stat. I Io. - I ziemlich defectes $0^{7}$.

Verbreitung: Pacifik.

3. Cylindroleberis inermis n. sp. Taf. 5, Fig. 6- $\mathrm{I} 3$.

Stat. I6. - I O

Schale des $\sigma^{\pi}$ ziemlich gestreckt, Höhe annähernd $1 / 2$ der Längè, Dorsal- und Ventralrand annähernd parallel, nach vorn wenig divergirend. Dorsalrand ziemlich deutlich durch eine stumpfwinklige Ecke gegen den gerundeten Hinterrand abgesetzt; Ventralrand flach S-förmig geschwungen. Oberfläche glatt, ohne Skulptur, Borstenreihe am Hinterrand dicht.

Die terminalen langen Borsten der I Antn. des o erreichen annähernd die doppelte Länge der Gliederreihe, die Klaue am dorsalen Rand des terminalen Gliedes einschlagbar. Innenast der 2 Antn. des $\sigma^{7}$ schlank, gestreckt, das 2. Glied mit einer Gruppe von 3 ziemlich kurzen Borsten etwas jenseits $1 / 2$ der Länge (zwischen $1 / 2$ und $2 / 3$ ); das einschlagbare Endglied so lang wie das 2., eine dünne, gewölbte Platte mit undeutlich gezähnten Rändern darstellend (Fig. 8, 9, r 3), in der Mitte dieser Platte sieht man eine unregelmässige Reihe von auffälligen 
Punkten, ich glaubte zunächst, dass es sich um kleine Wärzchen handle, spreche sie aber jetzt als Hypodermiskerne an. 'Im Profil erscheint das Glied schlank, mässig stark gebogen; nahe der Basis trägt es eine kurze Borste (kürzer als $1 / 4$ des ganzen Gliedes).

Putzfuss mit etwa Io Borsten und einer Doppelreihe dicht stehender, schlanker, wenig kräftiger Zähne.

Furca mit 7 schlanken, gleichmässig an Grösse abnehmenden Klauen; dieselben sind am, Hinterrand glatt, tragen keinerlei Besatz von Börstchen oder Spitzen; (bei ZeIss Syst. D vermochte ich noch keine zu entdecken, nur eine sehr undeutliche Zähnelung oder Strichelung des Chitinrandes); den Klauen folgen noch zwei Borsten.

Länge des $\sigma^{7}$ I,95 mm., $q$ unbekannt.

Wir kennen aus den östlichen Meeren verschiedene Vertreter der Gattung Cylindroleberis, bei denen die or einen ähnlichen Habitus zeigen, so australis (Brady r898, p. 43I, Taf. 43, Fig. I-8), grisea (ebenda p. 432, Taf. 43, Fig. 9-14), oculata (Brady 1902, p. I79, Taf. 2 I, Fig. 6-13). Auf die Schalenform ist für die Unterscheidung der Art kein zu grosses Gewicht zu legen, da dieselbe einigermaassen veränderlich, wichtig erscheint als Merkmal zur Unterscheidung der Mangel jeder Behaarung oder Bedornung am Hinterrand der Furcalklauen. Dadurch würde sich die Art von allen genannten sicher unterscheiden; auch würde mit Rücksicht auf dieses Merkmal keine der nur im weiblichen Geschlecht bekannten Arten in Frage kommen, und weiter würde sich durch dieses Merkmal das zugehörige $q$ leicht als solches erkennen lassen. Auch die Form deś Innenastes der 2 Antn. würde zur Unterscheidung von den genannten Arten genügen.

Von den Arten des atlantischen Oceans und Mittelmeers unterscheidet sich die Art ausser durch andere Merkmale durch das Längenverhältniss zwischen Gliederreihe und langen terminalen Borsten der I Antn. (bei $C$. inermis die Gliederreihe reichlich $1 / 2$, bei oblonga, mariae und augenscheinlich auch norvegica [cf. BRady und Norman I896, Taf. 52, Fig. 7] weniger als $1 / 2$ der längsten Borste).

\section{Cyclasterope Brady.}

I898. Cyclasterope G. S. Brady, I898, S. 85 .

I. Cyclasterope brevis (G. W. Müller).

I89I. Asterope brevis G. W. Müller, I89I, S. 239, Taf. 25, Fig. I0, Taf. 26, Fig. 7, Taf. 27, Fig. 7-I0, I5, I6.

Stat. $37 .-\mathrm{I}$ ㅇ․

Verbreitung: Pacifik, Kuiste von Japan. 


\section{VERZEICHNISS DER FUNDORTE.}

Station 6. - io März I899. $7^{\circ} 44^{\prime}$ S., I I $4^{\circ} 29^{\prime}$ Ö. Tiefe 29I M. Schlammigen Grund, Tiefsee-trawl. Cylindroleberis hilgendor fii.

Station r6. - r5/16 März. i 899. $6^{\circ} 59^{\prime}$ S., I 1 $5^{\circ} 24^{\prime}$ Ö. Bay von Kankamaraän. Tiefe 22 M. Vertikalnetz. Cypridina asymmetrica, Pyrocypris amphiacantha, Codonocera goniacantha, Cylindroleberis inermis.

Station 37. - 30/3i März. Paternoster-Inseln, Sailus Ketjil, dicht beim Riff. Tiefe 27 M. Plankton, Oberfläche. Conchoecia concentrica, Codonocera goniacantha, Cyclocypris brevis.

Station 40. - 2 April. Paternoster-Inseln, bei Kawassang. Tiefe I2 M. Plankton. Cypridina asymmetrica, Pyrocypris acuminata, sinuosa, inermis, dentata, serrata, lepidophora, Codonocera pusilla, goniacantha.

Station 47. - I2 April. Bay von Bima. Tiefe 55 M. Plankton. Cypridina asymmetrica.

Station 5I. - I9 April. Bay von Madura. Tiefe 69-9I M. Dredge und Trawl. 'Cylindroleberis hilgendorfii.

Station 66. - 7 Mai. Bank zwischen Bahuluwang und Tambolungan. Tiefe 8-io M. Plankton. Conchoecia bispinosa (I Q), Cypridina asymmetrica, Pyrocypris dentata, Codonocera zueberi, stellifera, penicillum.

Station 93. - 24 Juni. Abends. Pulu Sanguisiapo. Tiefe I2 M. Oberfläche. Codonocera weberi, polygonia, 'stellifera.

Station 96. - 27 Juni. Sulu-Archipel. Tiefe I5 M. Plankton. Cypridina asymmetrica, Codonocera cruenta, goniacantha.

Station 99. - 28/30 Juni. $6^{\circ} 7^{\prime}$ N., I $20^{\circ} 26^{\prime}$ Ö. North-Ubian. Tiefe I6-23 M. Oberfläche. Cypridina asymmetrica, hilgendorfii, Pyrocypris serrata, lepidophora, Codonocera weberi, cruenta, polygonia, stellifera.

Station I04. - 2/3 Juli. Sulu-Insel. Tiefe i4 M. Dredge und Townet. Codonocera weberi, Cylindroleberis hilgendorfi.

Station I06. - 4 Juli. Sulu-Archipel. Tiefe I3 M. Plankton. Cypridina faveola, Codonocera weberi, cruenta, polygonia, stellifera.

Station Iog. - 5 Juli. Abends. Sulu-Archipel. Tiefe 13 M. Plankton. Cypridina flaveola, Pyrocypris serrata, Codonocera stellifera.

Station I IO. -6 Juli. Abends. $4^{\circ} 34^{\prime} \mathrm{N}$., I $22^{\circ} \mathrm{o}^{\prime} \mathrm{O}$. Tiefe? Plankton. Cylindroleberis australis.

Station I I2. - 7 Juli. $3^{\circ}$ I N., $122^{\circ} 2^{\prime}$ Ö. Tiefe? Plankton. Conchoecia caudata.

Station II 7a. - I 2 Juli. ${ }^{\circ} 5 I^{\prime}$ N., I $23^{\circ} 37^{\prime}$ Ö. Tiefe? Plankton. Pyrocypris acuminata, Codonocera weberi.

Station i25. - i8/19 Juli. Siau-Insel. Tiefe 27 M. Plankton. 'Codonocera goniacantha.

Station I28. - 22 Juli. $4^{\circ} 27^{\prime}$ N., I $25^{\circ} 25^{\prime}$ Ö. Tiefe I645 M. Vertikalnetz von 700 M. zur Oberfläche. Conchoecia imbricata. 
Station 129. - 22/23 Juli. Bei Kawio- und Kamboling-Inseln. Tiefe 23-3I M. Plankton. Codonocera stellifera.

Station i 36. - 29 Juli. Ternate. Tiefe 23 M. Plankton. Codonocera weberi, 'stellifera.

Station i38. - 3 Aug. Ostküste der Kajoa-Insel. Tiefe 66 M. Plankton. Codonocera penicillum.

Station I4I. - 5 Aug. $1^{\circ} \mathrm{O}^{\prime}$ S., $127^{\circ} 25^{\prime}$ Ö. Tiefe 1950 M. Verticalnetz von I 500 M. zur Oberfläche. Halocypris cornuta, Conchoecia spinifera, caudata, procera, bispinosa, striola, atlantica, loricata, ctenophora, macrocheira, magna, spinirostris, mollis (?), ametra, imbricata, leptothrix, lophura, sibogae, Cypridina castanea.

Station 143. - 7 Aug. $1^{\circ} 4^{\prime}$ S., $127^{\circ} 52^{\prime}$ Ö. Tiefe I454 M. Verticalnetz von IOoO M. zur Oberfläche. Halocypris cornuta, Conchoecia caudata, sibogae.

Station 144. - 7/9 Aug. Nördlich von der Insel Salomakiëe. Tiefe 45 M. Plankton. Codonocera weberi, goniacantha.

Station I48. - io Aug. $0^{\circ}$ I7' S., I29 I4' Ö. Tiefe 1855 M. Vertikalnetz von IOOo M. zur Oberfläche. Conchoecia elegans, acuminata, bispinosa, atlantica, lophura, magna, ametra, leptothrix, sibogae.

Station I64. - 20 Aug. $I^{\circ} 42^{\prime}$ S., $130^{\circ} 47^{\prime}$ Ö. Tiefe 32 M. Sarsiella sp.

Station 172. - 26/28 Aug. Zwischen Insel Gisser und Ceram Laut. Tiefe i8 M. Plankton. Codonocera weberi.

Station I8I. - 5/I I Sept. Ambon. Tiefe 36-54 M. Cypridina hesperida.

Station 185. - 12 Sept. $3^{\circ} 20^{\prime}$ S., $127^{\circ} 22^{\prime}$ Ö. Manipa-Strasse. Tiefe mehr als 1536 M. Verticalnetz von 1536 M. zur Oberfläche. Halocypris cornuta, Conchoecia caudata, acuminata, bispinosa, atlantica, loricata, ctenophora, lophura, macrocheira, mollis (?), plinthina, leptothrix, sibogae.

Station I94. - I5 Sept. I $53^{\prime}$ S., I $26^{\circ} 39^{\prime}$ Ö.L. Tiefe 1504 M. Horizontalnetz. Conchoecia rotundata.

Station 203. - I9 Sept. $3^{\circ} 23^{\prime}$ S., I $24^{\circ}$ I 5 Ö. Tiefe 4892 M. Verticalnetz von I 500 M. zur Oberfläche. Halocypris globosa, Conchoecia caudata, elegans, procera, bispinosa, striola, atlantica, mollis('s), leptothrix.

Station 21 I. -25 Sept. $5^{\circ} 40^{\prime}$ S., $120^{\circ} 45^{\prime}$ Ö. Tiefe II 58 M. Tiefeetrawl, Grund grober, grauer Schlamm, das oberflächliche Lager flüssiger und braun. Crossophorus gibber.

Station 216. - 30 Oct. $6^{\circ} 49^{\prime}$ S., $122^{\circ} 43^{\prime}$ Ö. Tiefe 2190 M. Schliessnetz von 975-415 M. Conchoecia striola. I ㅇ.

Station 230. - I4 Nov. $3^{\circ} 58^{\prime}$ S., I $28^{\circ} 20^{\prime}$ O. Vertikalnetz aus 2000 M. bis zur Oberfläche. Halocypris cornuta, Conchoecia caudata, mollis (?).

Station 243. - 2 Dec. $4^{\circ} 30^{\circ}$ S., $129^{\circ} 25^{\prime}$ Ö. Vertikalnetz aus Iooo M. bis zur Oberfläche. Halocypris inflata, cornuta, Conchoecia oblonga, echinata, caudata, elegans, procera, rotundata, curta, bispinosa, striola, atlantica, loricata, ctenophora, iophura, macrocheira, subarcuata, magna, spinirostris, mollis (?), daphnoides.

Station 260. - ${ }_{16}$ Dec. $5^{\circ} 36^{\prime}$ S., I $32^{\circ} 55^{\prime}$ Ö. Tiefe 90 M. 2,3 Meilen nördlich vom Nord-Punkt von Nuhu Jaan, Kei-Insel; Grund Sand, Korallen und Schalen, Blake dredge. Cylindroleberis hilgendorfii, I Indiv.

Station 276. - 9 Jan. I900. $6^{\circ} 47^{\prime}$ S., I $28^{\circ} 40^{\prime}$ Ö. Vertikalnetz aus 750 M. zur Oberfläche. Conchoecia spinifera, oblonga, echinata, caudata, procera, acuminata, parthenoda, bispinosa, atlantica, subarcuata, magna, spinirostris, imbricata, concentrica.

Station 282. - I5/17 Jan. $8^{\circ} 25^{\prime}$ S., $127^{\circ} 18^{\prime}$ Ö. Tiefe 27-54 M. Ankergrund zwischen Nusa Besi und der Nordostspitze von Timor. Plankton, Oberfläche. Conchoecia acuminata, concentrica.

Überblicken wir die obige Zusammenstellung, so ergiebt sich, dass die Halocypriden fast ausnahmslos an Stellen mit grosser Tiefe (über $75^{\circ}$ M.), die Cypridiniden, soweit sie freischwimmend gefangen sind, an Stellen mit geringer Tiefe (weniger als zo M.) gefangen sind. Deutlicher tritt das in der folgenden Übersicht der planktonischen Fänge hervor. 


\begin{tabular}{|c|c|c|c|c|c|c|c|}
\hline Station. & Tiefe. & $\begin{array}{l}\text { Zahl } \\
\text { Haloc. }\end{array}$ & $\begin{array}{l}\text { der Arten } \\
\text { von } \\
\text { | Cypridin. }\end{array}$ & Station. & Tiefe. & $\mid \begin{array}{r}\text { Zahl d } \\
\text { Haloc. }\end{array}$ & $\begin{array}{l}\text { der Arten } \\
\text { von } \\
\text { Cyprídin. }\end{array}$ \\
\hline I 6 & 22 & . & 4 & 138 & 66 & . & I \\
\hline 37 & 27 & I & 2 & I $4 \mathrm{I}$ & 1950 & 18 & I \\
\hline 40 & 12 & . & 9 & I 43 & 1454 & 3 & . \\
\hline 47 & 55 & - & I & 144 & 45 & . & 2 \\
\hline 66 & $8-10$ & $\mathbf{I}$ & 5 & $14^{8}$ & 1855 & 9 & . \\
\hline 93 & 12 & . & 3 & 164 & 32 & - & $\mathbf{I}$ \\
\hline 96 & 15 & . & 3 & 172 & 18 & . & 1 \\
\hline 99 & $16-23$ & . & 8 & I 81 & $36-54$ & - & I \\
\hline 106 & 13 & . & 5 & 185 & über I 536 & 13 & . \\
\hline 109 & 13 & . & 3 & I94 & 1504 & I & . \\
\hline I Io & $?$ & - & I & 203 & 4892 & 9 & . \\
\hline II 2 & $?$ & I & - & 216 & 2190 & I & . \\
\hline $117^{\mathrm{a}}$ & $?$ & - & 2 & $23^{\circ}$ & über 2000 & 3 & . \\
\hline I 25 & 27 & . & $\mathbf{I}$ & 243 & úber 1000 & $2 I$ & . \\
\hline I 28 & I645 & I & . & 276 & über 750 & 14 & . \\
\hline 129 & $23-3 I$ & . & I & 282 & $27-54$ & 2 & . \\
\hline 136 & 23 & . & 2 & & & & \\
\hline
\end{tabular}

Die Übersicht zeigt deutlich den Unterschied im Vorkommen der Halocypriden und Cypridiniden; die beiden Familien schliessen sich bis auf vereinzelte Funde weniger Individuen vollständig aus; die Fundorte characterisiren sich durch grosse oder geringe Tiefe. Das Vorkommen der Cypridiniden scheint die früher (G. W. Müller, I89I, p. 2 I I) ausgesprochene Anschauung zu bestätigen, dass die Cypridiniden den Grund des Meeres bewohnen gelegentlich zur Oberfläche aufsteigen; wenigstens finde ich in dieser Anschauung die einfachste Erklärung für die oben festgestellte Thatsache.

Allerdings erleidet die Regel mancherlei Ausnahmen, wir kennen zahlreiche Formen, welche unzweifelhaft dauernd an den Grund gebunden sind (Pseudophilomedes und andere), sowie solche, die nach ihrem ganzen Bau auf eine ausschliesslich pelagische Lebensweise angewiesen sind (Gigantocypris).

Bei den Halocypriden kann man, glaube ich, die an anderem Ort (I 894, p. I3) von mir ausgesprochene Ansicht, dass sie sich dauernd am Grund aufhalten, nur zeitweis freischwimmend aufsteigen, allerding für längere Zeit, nach den hier niedergelegten und bei anderen Gelegenheiten gesammelten Erfahrungen (vergl. die Bearbeitung der Valdivia-Ostracoden I906) nicht aufrecht erhalten. So wenig mir der Bau ihres Körpers zu einer ausschliesslich pelagischen Lebensweise $\mathrm{zu}$ passen scheint, so zwingt doch ihr Vorkommen auf hoher See, weit von den Küsten und über grossen Tiefen, besonders aber das Fehlen in der Nähe der Küste und über geringen Tiefen (vergl. die obige Übersicht) zur Annahme einer solchen Lebensweise.

Wenn wir jetzt die Eingangs (S. I) aufgeworfene Frage wiederholen, ob der Reichthum der Siboga-Ostracoden an Cypridiniden aus der besonderen Art des Sammelns oder aus dem Reichthum der untersuchten Lokalitat zu erklären ist, so möchte ich sie zunächst im ersten Sinn beantworten. Häufiger als andere wissenschaftliche Expeditionen hat, so weit ich das zu übersehen vermag, die Siboga vor Anker gelegen und in der Nähe des Landes auf flachem Grund pelagische Organismen gefischt. Allerdings dürfte auch der malaysche Archipel mit seinen zahlreichen Inseln und seiner so ausserordentlich reichen Küstenbildung der geeignetste Boden sein für eine Tiergruppe mit der Lebensweise der Cypridiniden. 


\section{VERZEICHNISS DER CITIRTEN ARBEITEN.}

AURIVILlius, C. W. S. 1898. Vergleichend tiergeographische Untersuchungen über die Plankton-Fauna des Skageraks in den Jahren 1893-1897 in: Kgl. Svenska Vetenskaps-Akademiens Handlingar. Neue Folge vol. I $3, \mathrm{~N}^{0} 3$.

BRADY, G. S. I866. On new or imperfectly know species of marine Ostracoda. in: Transactions of the zoological society of London, vol. 5, 1866, S. 359-393.

- I 1868. Synopsis of recent British Ostracoda in: Intellectual Observer v. 12, I867 (1868), S. Iro.

- I I880. Ostracoda in: Report of the Voyage of H. M.S. Challenger, vol. I, part 3.

- - I890. The Ostracoda collected by H. B. BRADY in the south sea islands in: Transactions of the R. Society of Edinburgh. Vol. 35, Part 2, S. 489-525.

- - 1898. Supplementary Report on the Crustaceans of the Group Myodocopa etc. Challenger-expedition in: Transactions of the zoological society of London, vol. 14, S. 85- roo.

- I898. On new or imperfectly-known Species of Ostracoda, chiefly from New-Zealand. ebenda S. $429-452$.

- 1902. On new or imperfectly-know Ostracoda, chiefly from a Collection in the zoological Museum, Copenhagen. ebenda vol. I6, S. 179--202.

und Norman. I896. A Monograph of the marine and freshwater Ostracoda of the North-Atlantic and of North Western Europe. Part II in: Transactions of the Royal Dublin Society. Vol. 5, Ser. 2, S. $62 \mathrm{I}-743$.

Claus, C. I873. Neu Beobachtungen über Cypridinen in: Zeitschr. wissenschaftl. Zoologie. Vol. 23, S. 2 I I ff.

- I874. Die Familie der Halocypriden in: Schriften zoologischen Inhalts. Heft I, Wien 1874.

- - r890. Die Gattungen und Arten der mediterranen und atlantischen Halocypriden in: Arbeiten aus dem zoologischen Institut Wien. Vol. 9, Heft r.

- I $891 a$. Das Medianauge der Crustaceen. ebenda vol. 9, Heft 3.

- - I89r. Die Halocypriden des atlantischen Oceans und Mittelmeers. Wien I89I.

-_ 1894. Die Halocypriden des östlichen Mittelmeers in: Denkschriften der Akademie Wien. Vol. 6r.

DANA, J. I852. United States exploring expedition during I837-I842. Vol. I3.

JudAY, C. I906. Ostracoda of the San Diego region. I. Halocypridae in: University of California Publications. Zoology, vol. $3, \mathrm{~N}^{0} 2^{1}$ ).

Lubbock J. 1856. On some Entomostraca collected by Dr. Sutherland in the atlantic Ocean in: Transactions of the entomological Society London. New series, vol. 4, S. 28.

- 1860. On some Oceanic Entomostraca collected by Capt. ToynbeE in: Transactions of the Linnean Society of London, vol. 23, S. I86-190.

I) Die Arbeit ging mir erst nach Ablieferung des Manuskriptes zu. Ich vermag zur Zeit nicht festzustellen, ob sie den ValdiviaOstracoden (G. W. MÜLLER 1906) gegenüber die Priorität besitzt, was zur Änderung einiger Namen führen würde. Das Heft trägt das Datum 9. April 1906, doch ist nicht ersichtlich, ob es sich um den Zeitpunkt des Erscheinens oder um Einlieferung des Manuskripts handelt. Ich erhielt das Heft am 18 Juni 1906. 
MÜLLER, G. W. I8gr. Neue Cypridiniden und Über Halocypriden in: Zoolog. Jahrbücher. Abtheilung für Systematik, vol. 5, p. 2 I I- 252 und $253-280$.

_- I894. Die Ostracoden des Golfes von Neapel in: Fauna und Flora des Golfes von Neapel, vol. 2 I.

- - I895. Ostracoden des Reports Dredging Albatross in I89 I ( $\mathrm{N}^{0} \mathrm{I} 9$ ) in: Bulletin of the Museum of comparative Zoology, vol. $27, \mathrm{~N}^{0} 5$.

- I Igor. Ostracoden in: Nordisches Plankton von K. Brandt. $\mathrm{N}^{0} 7$, Kiel $190 \mathrm{I}$.

- I I06. Ostracoda in: Wissenschaftliche Ergebnisse der deutschen Tiefseeexpedition. Vol. 8, S. 29-154.

NORMAN. I868. Last report on dredging among the Shetland Isles in: Report british association for the advancement of science for 1868 , S. $248-294$.

Philippi, A. i840. Zoologische Bemerkungen in: Archiv für Naturgeschichte, vol. 6, I840.

SARS, G. O: I865. Översigt of Norges marine Ostracoder in: Forhandlinger i Videnskabs-Selskabet i Christiania 1865.

1887. Ostracoda mediterranea in: Archiv for Mathematik og Naturvidenskab. (Christiania). Vol. 12, I887. I 89 r. Översigt af Norges Crustaceer med forelobige Bemaerkinger over de nye eller minunde bekjendte Arter II in: Forhandlinger i Videnskabs-Selskabet i Christiania I 890, $\mathrm{N}^{0}$ I.

I900. Crustacea in: Scientific Results of the Norwegian North-Polar-Expedition 1893-96, vol. I, N0 5 .

ScotT, Th. I894. Report on Entomostraca from the Gulf of Guinea in: Transactions of the Linnean society of London, vol. 6, part I, S. I4I-I44.

1902. Notes on gatherings of Crustacea collected by the fischery steamer Garland in: Annual Report on the Fishery Board for Scotland for I90I. Vol. 20, I902. Part 3. scientific investigations. S. 475 .

Stebbing, F. R. R. igoo. On Crustacea brought by Dr. Willey from the south seas in: A. Willey's zoological Results. Part 5, Cambridge 1900, S. 659-663.

1902. South African Crustacea II in: Marine invastigations in South Africa (Cape of Good Hope, Departement of Agricultare. 12, 1901), S. 77 .

VAVRA, W. 1906. Die Ostracoden der Planktonexpedition. (Ergebnisse der Planktonexpedition. Vol. II G. g. Kiel und Leipzig 1896.

Watanabe, H. The Phosphorescence of Cypridina hilgendorfii Müller in: Annotationes zoologicae japonenses. Vol. I, Tokyo I897, S. 69. 
TAFELN

Figurenerklärung.

Fr. Frontalorgan.

I.R. Innenrand.

L. Leiste.

1. Dr. laterale Drüse.

M. Muskel.

p. paarig.

$\mathrm{P}_{3}$. 3. thoracale Gliedmaasse.
R. Schalenrand.

S. Saum.

S.L. Schlossleiste.

u. Dr. unpaare Drüse. u.p. unpaar.

Vl. Verwachsungslinie. 


\section{TAFEL I.}

Fig. I-9. Conchoecia concentrica. S. IO.

Fig. I, 2. Schale des $\sigma^{7} \mathrm{im}$ Profil und von der Ventralseite. $70 \times$ und $58 \times$.

Fig. 3. Innenast der rechten 2. Antn. des $\sigma^{7} \cdot 90 \times$.

Fig. 4, 5. Hakenglied der rechten und linken 2. Antenne. I $54 \times$.

Fig. 6. Frontalorgan und I. Antn. des $q$ (Borsten gekürzt). $154 \times$.

Fig. 7. Stück der Hauptborste der I. Antn. des $0^{7} \cdot 270 \times$.

Fig. 8. Frontalorgan und I. Antn. des $\sigma^{7}$. $154 \times$.

Fig. 9. Rechte hintere ventrale Ecke von der medialen Seite. $154 \times$.

Fig. 10-20. Conchoecia sibogae. S. 8.

Fig. IO. Frontalorgan und I. Antn. des $q .90 \times$.

Fig. II. Rechte hintere ventrale Ecke von der medialen Seite. I54 $\times$.

Fig. 12. Stück der Hauptborste der I. Antn. $270 \times$.

Fig. 13. Schale des $\sigma^{\top} \cdot 34 \times$.

Fig. I4. Hinterrand der ausgebreiteten Schale. $58 \times$.

Fig. I 5. Endstuick des Frontalorgans des $\sigma^{7}$ von der Ventralseite. I $54 \times$.

Fig. 16. I. Antn. und Frontalorgan des $\sigma^{7} .58 \times$.

Fig. I7 wie I5. Profil. I $54 \times$.

Fig. I 8, 19. Hakenglied der linken und rechten 2. Antn. des $0^{7}$. I54 $\times$.

Fig. 20. Innenast der 2. Antn. des $\sigma^{7} \cdot 90 \times$. 
Siboga-Expeditie. XXX. G. W. Müler, Ostracoda.

r.

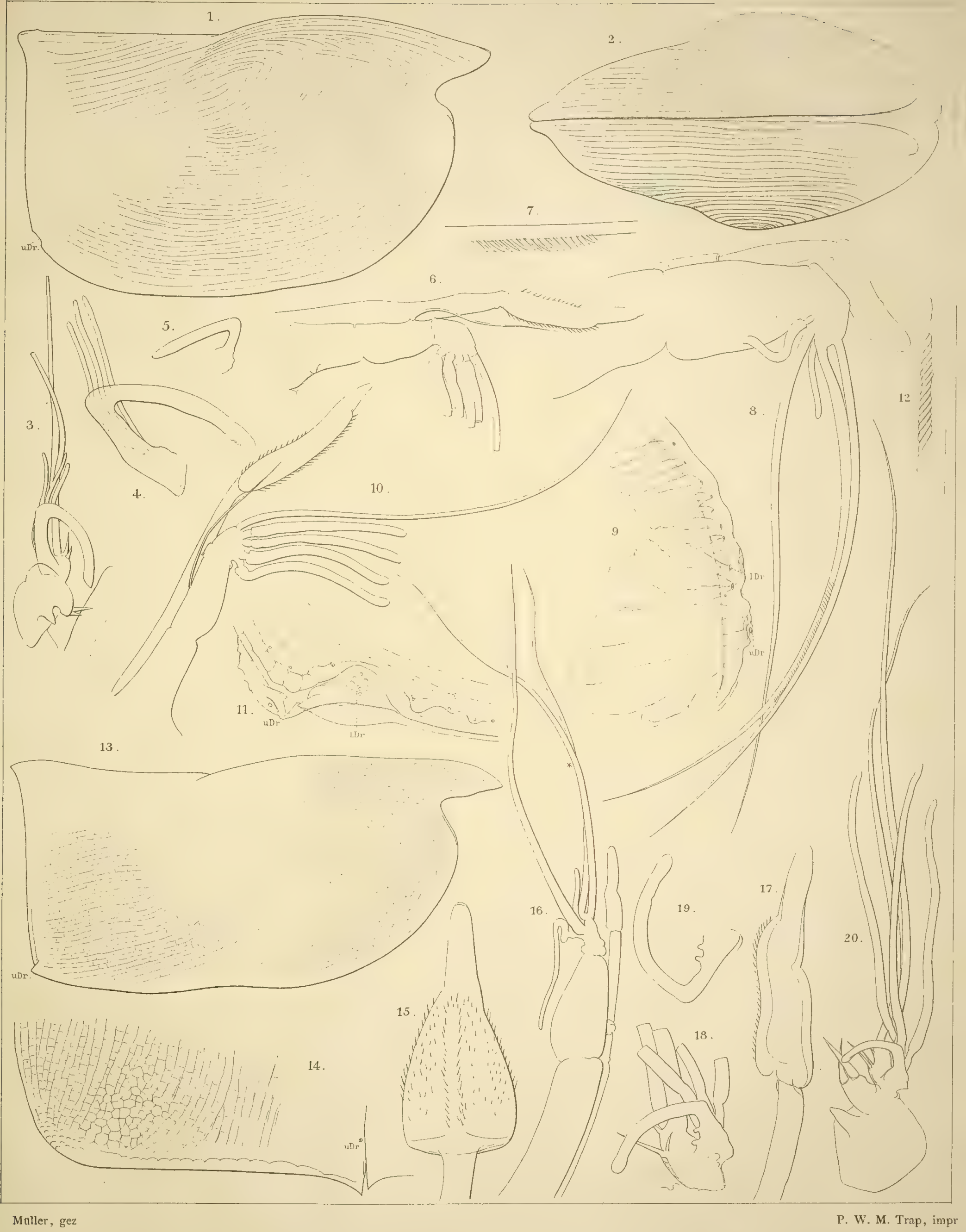






\section{TAFEL II.}

Fig. 1-5. Pyrocypris acuminata ${ }^{7}$. S. 18.

Fig. I. Schale des $\sigma^{7}$ mit ausgestreckten Borsten der 1. Antn. $46 \times$.

Fig. 2. Innenast der 2. Antn. I $54 \times$.

Fig. 3. Rechter Furcalast. I $8 \times$.

Fig. 4. Vorderrand der Schale von der medialen Seite. $154 \times$.

Fig. 5. Hinterende von der medialen Seite. I $54 \times$.

Fig. 6-10. Pyrocypris inermis. S. I9.

Fig. 6. Hinteres Schalenende von der medialen Seite. II $8 \times$.

Fig. 7. $\sigma^{7}$ im Profil, man sieht die Basis der Furca sowie die um den Hinterrand des Körpers herumgeschlagenen langen Borsten der I. Antn., die in der Nachbarschaft des Auges endigen. $58 \times$.

Fig. 8. Innenast der 2. Antn. $154 \times$.

Fig. 9. Vorderer Schalenrand von der medialen Seite. II $8 \times$.

Fig. IO. Linker Furcalast und Vorderrand des rechten Astes. $154 \times$.

Fig. II-16. Pyrocypris simuosa. S. I9.

Fig. II. Rechter Furcalast. I $54 \times$.

Fig. 12. $0^{7}$ im Profil. 58 x.

Fig. 13. Innenast der 2 Antn. $154 \times$.

Fig. 14. Vorderrand der Schale von der medialen Seite. $154 \times$.

Fig. I5, I6. Rechtes und linkes Hinterend von der medialen Seite. I54 $\times$.

Fig. I7-2I. Pyrocypris dentata. S. 20.

Fig. I7. Schale des $0^{7} \cdot 46 \times$.

Fig. I8. Hinterende der linken Schale von der medialen Seite. I $18 \times$.

Fig. 19. Vorderrand der Schale unterhalb der Incisur von der medialen Seite. $270 \times$.

Fig. 20. Vorderrand der Schale von der medialen Seite. II $8 \times$.

Fig. 21. Rechter Furcalast. $154 \times$. 
Silingra-Expeditie. XXX. G. W. Muller, Ostracoda.

11.

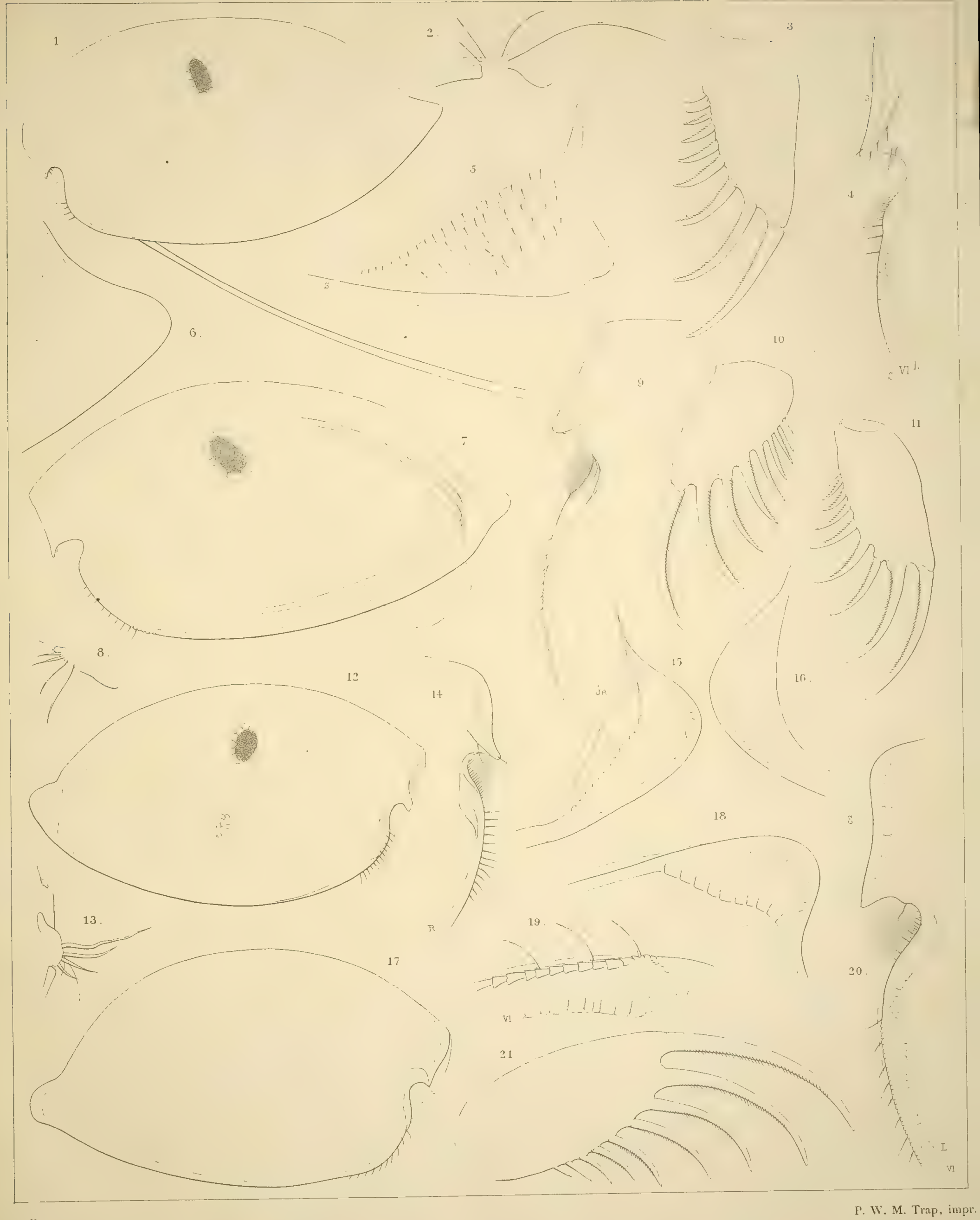



.

$$
\text { · }
$$




\section{TAFEL III.}

Fig. I-7. Pyrocypris serrata 07. S. 20.

Fig. I. Linke Schale des $0^{7} \cdot 46 \times$.

Fig. 2, 3. Hinterende der rechten und linken Schale von der medialen Seite. I $8 \times$.

Fig. 4. Vorderrand von der medialen Seite. $154 \times$.

Fig. 5. Rechter Furcalast. $154 \times$.

Fig. 6. Oberlippe. I $54 \times$.

Fig. 7. Innenast der 2. Antn. $154 \times$.

Fig. 8-12. Pyrocypris amphiacantha 07. S. 21.

Fig. 8. Linke isolirte Schale des $0^{7} \cdot 58 \times$.

Fig. 9. Vorderrand von der medialen Seite. I $18 \times$.

Fig. Io. Innenast der 2. Antn. $154 \times$.

Fig. I I. Rechter Furcalast. I $54 \times$.

Fig. I2. Ende des Schlossrandes und Hinterende beider Schalen von der medialen Seite; die Schlossleiste Sl der linken Schale fügt sich zwischen die beiden Schlossleisten der rechten. I 8 $\times$.

Fig. I3-20. Pyrocypris lepidophora. S. 2I.

Fig. I3. Schale des $9.46 \times$.

Fig. I4, I5. Hinterende der rechten und linken Schale von der medialen Seite. 154 $\times$. (Fig. I 5 ist irrthümlich im Spiegelbild gezeichnet).

Fig. I6. Innenast der 2. Antn. $154 \times$.

Fig. I7, I8. Vorderrand von der lateralen und medialen Seite gesehen. I54 $\times$.

Fig. I9. Linker Furcalast und Vorderrand des rechten. I $54 \times$.

Fig. 20. I.-3. Glied der 2. Antn. $154 \times$.

Fig. 2I-27. Cypridina hesperida. S. I5.

Fig. 2I. Linke Schale $46 \times$.

Fig. 22. Linker Furcalast und Vorderrand des rechten; der 2. Dorn abgebrochen, derselbe ordnete sich nach Grösse und Form zwischen die benachbarten, so dass die Dornen gleichmässig an Grösse und Umfang abnehmen. II $8 \times$.

Fig. 23. Hinterende eines ganzen Thieres (beide Schalen). $42 \times$.

Fig. 24. 3. Furcaldorn von der lateralen Seite. $270 \times$.

Fig. 25. Hinterende der rechten Schale. $42 \times$.

Fig. 26. Putsfuss. $154 \times$, der Bau der Borsten nur an 3 Borsten gezeichnet.

Fig. 27. Oberlippe. $154 \times$.

Fig. 28. Cypridina monopia, junges $\circ$. Frontalorgan im optischen Sagittalschnitt. $90 \times$. 
Siloga-Expeditie. XXX. G. W. MuLler, Ostracoda.

III.

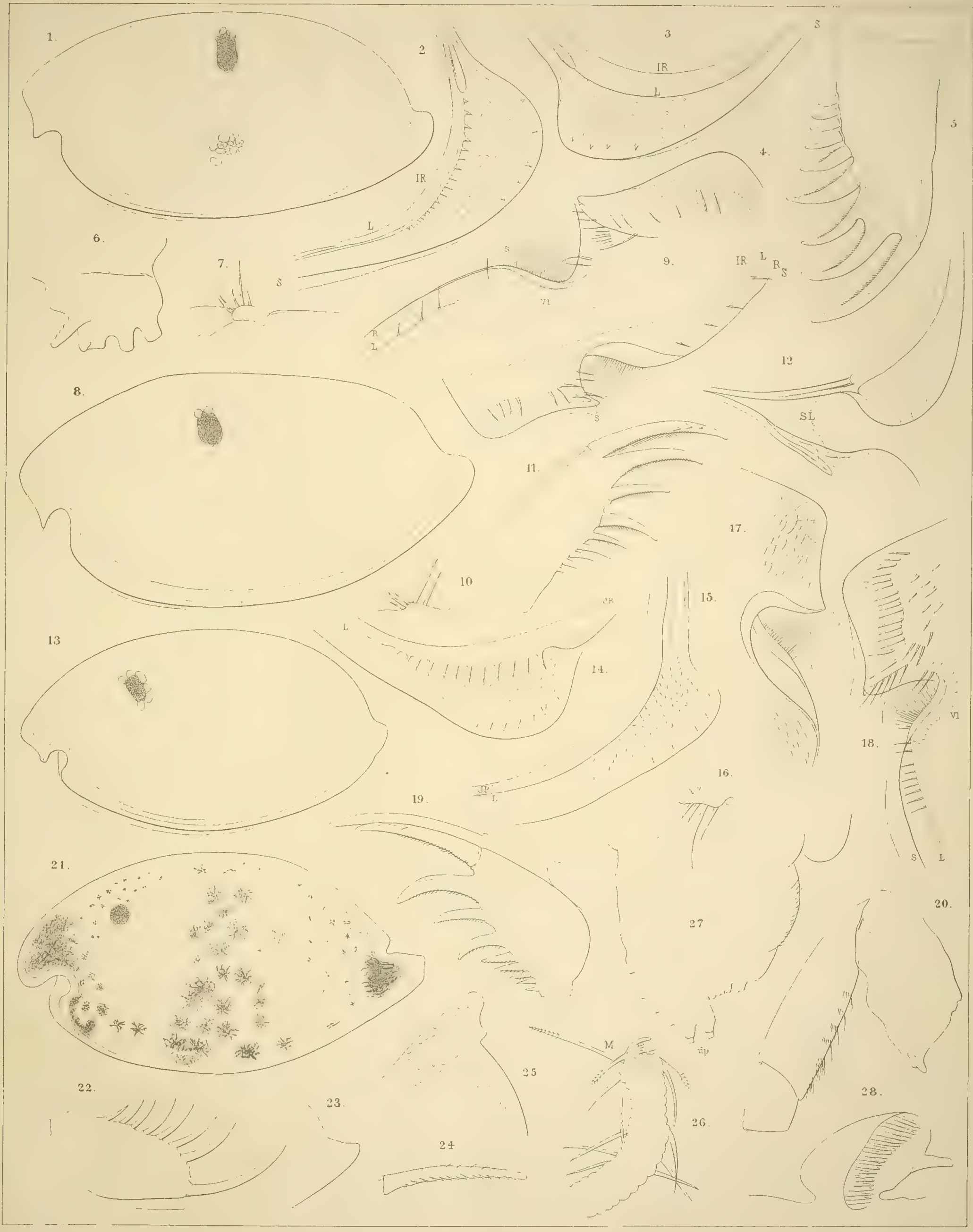

Muller, gez.

P.W. M. Trap, impr. 




\section{TAFEL IV.}

Fig. I-9. Crossophorus gibber ơ. S. 28.

Fig. I. Schale. I $8 \times$.

Fig. 2. Oberlippe. $43 \times$.

Fig. 3. I. Antn. $58 \times$.

Fig. 4. Linker Furcalast. 58.

Fig. 5. 2. thoracale Gliedmaasse. $58 \times$.

Fig. 6. Innenast der 2. Antn. $68 \times$.

Fig. 7. Spitze des Putsfusses. I $54 \times$ (sehr defect, vergl. S. 29).

Fig. 8. Stück einer Borste des letzten Gliedes der I. Antn. I $54 \times$.

Fig. 9. Die 2 letzten Glieder der I. Antn. $90 \times$.

Fig. 10-I8. Sarsiella sp. $0^{7}$ juv. S. 30.

Fig. Io. Schale. $90 \times$.

Fig. I I. Mandibel. I $54 x$.

Fig. I2. I. Thoraxbein (2. Maxille). $270 \times$.

Fig. I3, I4. Maxille in verschiedener Lage. $270 \times$.

Fig. 15. Furca, Genitalhöcker und Putsfuss. I $54 \times$.

Fig. 16. Zweites Thoraxbein. $270 \times$.

Fig. 17. 2. Antn. I54 $\times$ (alle Borsten des Aussenastes in ähnlicher Weise bedornt, wie bei einer gezeichnet).

Fig. I8. r. Antn. $270 \times$. 


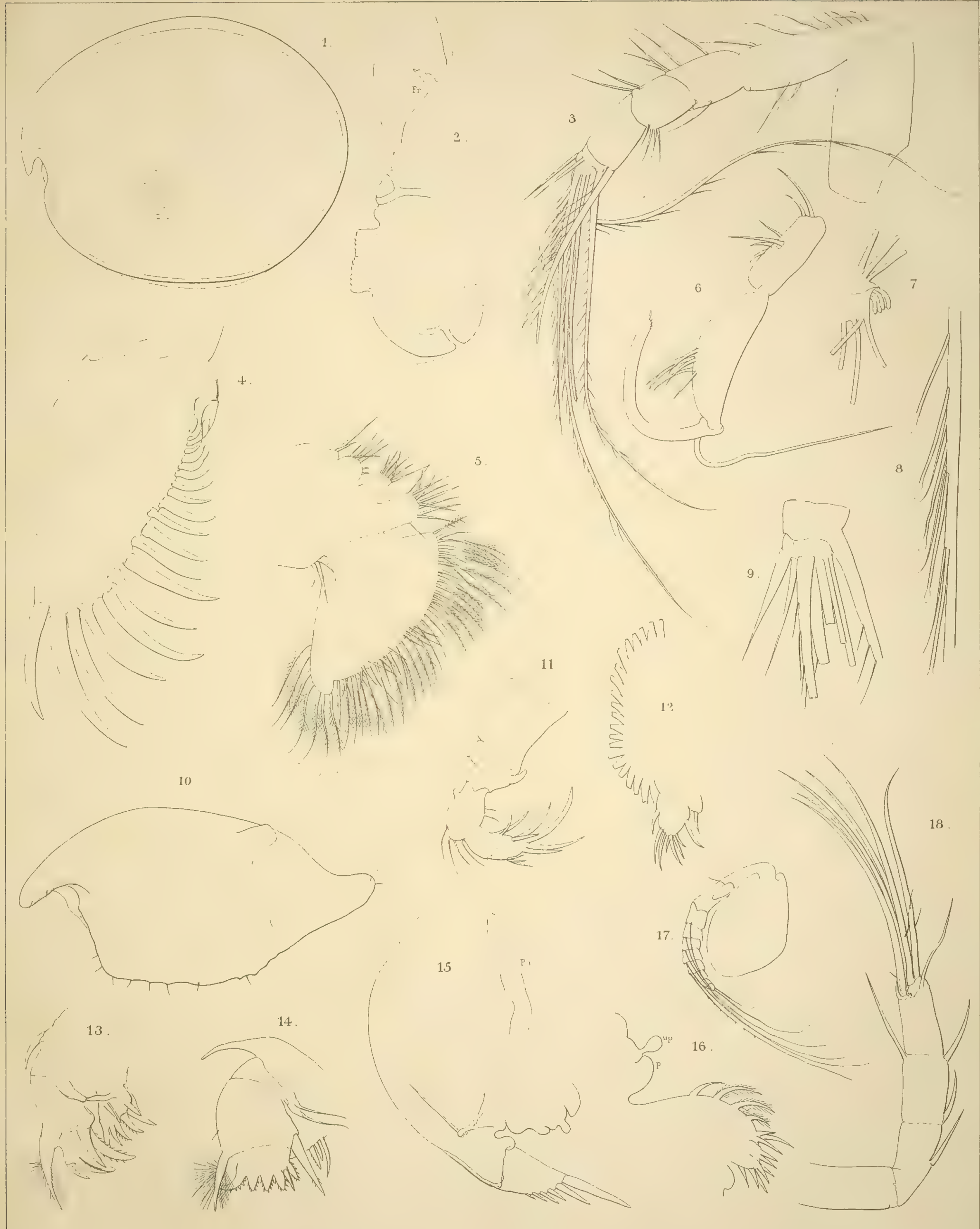





\section{TAFEL V.}

Fig. I-5. Cylindroleberis hilgendorfii o'. S. 33 .

Fig. - I. Rechte Schale. I7 $\times$.

Fig. 2. Vorderrand der rechten Schale. $30 \times$.

Fig. 3. Erste Antenne, Frontalorgan und Oberlippe. $32 \times$.

Fig. 4. Innenast der 2. Antn. $70 \times$.

Fig. 5. Endstück des terminalen Gliedes des Innenastes. I $54 \times$.

Fig. 6-13. Cylindroleberis inermis o7. S. 34 .

Fig. 6. Ende des Putsfusses, von einigen Borsten ist nur die Basis gezeichnet. $270 \times$.

Fig. 7. Schale. $45 \times$.

Fig. 8, 9. Die zwei terminalen Glieder des Innenastes der 2. Antn. in verschiedener Stellung. $154 \times$.

Fig. IO. Die zwei letzten Glieder der I. Antn., die Klaue gestreckt. I $54 \times$.

Fig. II. Das hintere Körperende mit Penis, Furca und Kiemenblättern. $90 \times$.

Fig. I2. I. Antn.; die Klaue eingeschlagen. $90 \%$.

Fig. I3. Innenast der 2. Antn. I $54 \times$. 
Siboga-Expeditie. XXX. G. W. MüLler, Ostracoda.

I:

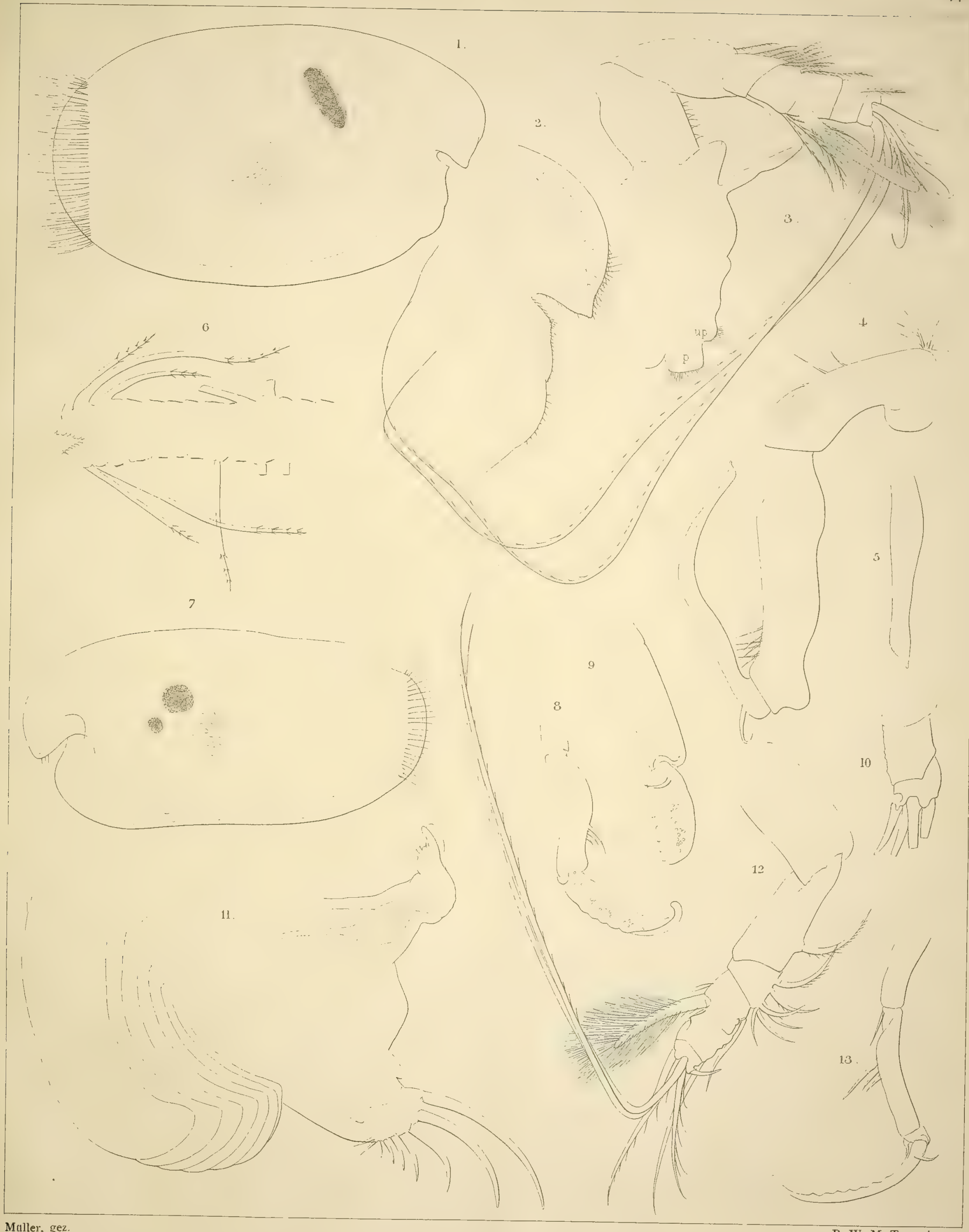

Maller, gez.

P. W. M. Trap, impr. 

(2)

, 


\section{TAFEL VI.}

Fig. I-I2. Cypridina asymmetrica. S. I4.

Fig. I, 2. Linke und rechte Schale des $0^{7} \cdot 46 \times$.

Fig. 3. Schalenskulptur von der Mitte der Schale, im Centrum eine Grube. I54 $\times$.

Fig. 4. Furca (mit beiden Ästen), Hinter- und Dorsalrand des Körpers des $0^{7} \cdot 58 \times$.

Fig. 5. Oberlippe, Frontalorgan und paariges Auge. $90 \times$.

Fig. 6. Vorderrand der Schale von der medialen Seite. $90 \times$.

Fig. 7. Zweite thoracale Gliedmaasse. I $54 \times$.

Fig. 8. Spitze des Putsfusses, Zange geöffnet. I $54 \times$.

Fig. 9. Greifborste der I. Antn. des $0^{7} .206 \times$.

Fig. I0. Distales Stück des Putsfusses, soweit mit Borsten besetzt, Zange geschlossen. I $54 \times$.

Fig. I I. Innenast und die 2 proximalen Glieder des Aussenastes der 2. Antn. $90 \times$.

Fig. I2. Penis. I $54 \times$.

Fig. I3-I6. Codonocera stellifera. S. 27 .

Fig. I3. Oberlippe, Frontalorgan, paariges Auge und I. Antn. des $0^{7} \cdot 46 \times$.

Fig. I4. Die 3 letzten Glieder der I Antn. des OJ, die Borsten z. Th. gekürzt. I $54 \times$.

Fig. I 5. Greifborste der I. Antn. des $\sigma^{7} .270 \times$.

Fig. I6. Vorderrand des I. Gliedes der I. Antn. des $q$. I $54 \times$. 


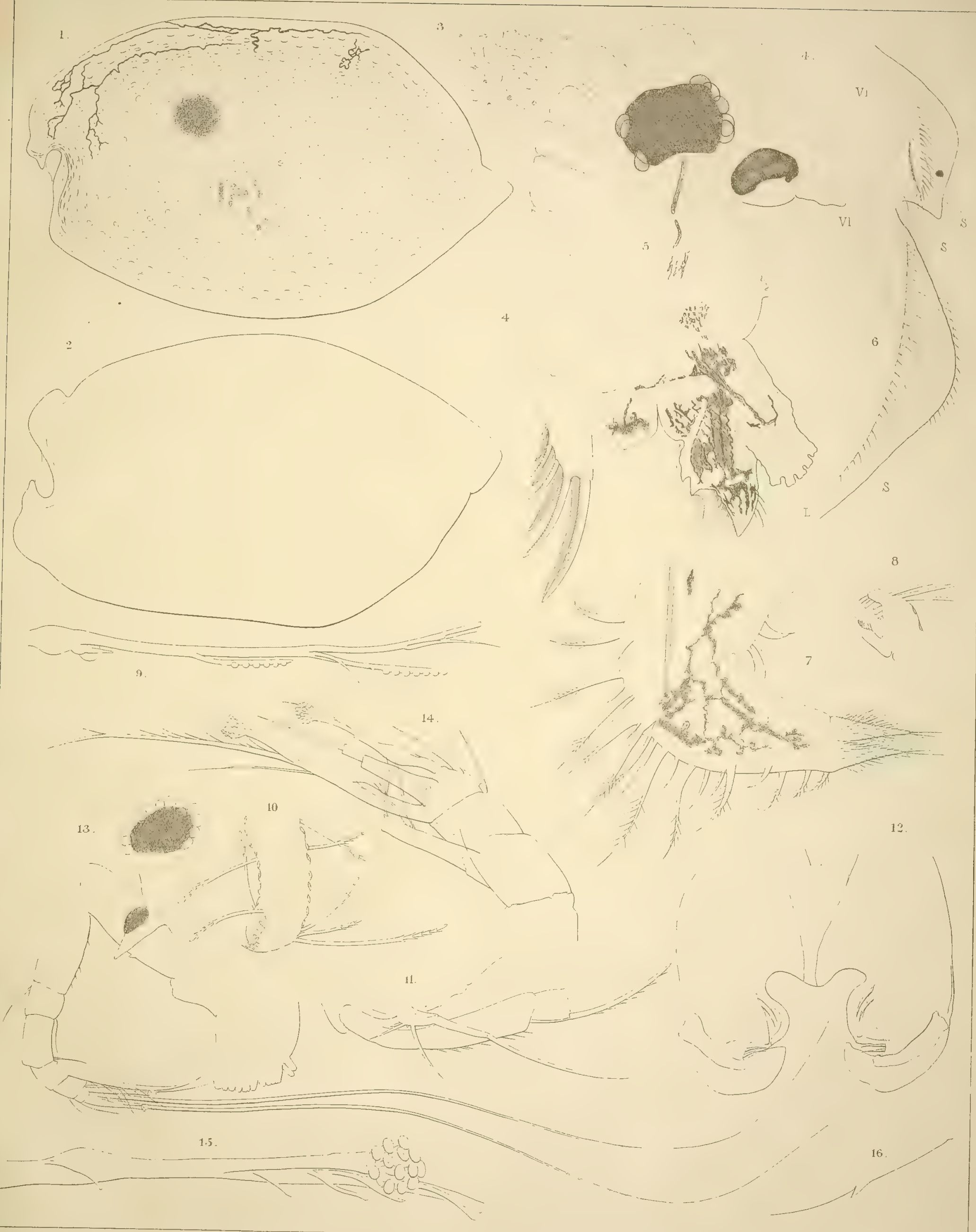






\section{TAFEL VII.}

Fig. I-9. Codonocera stellifera. S. 27.

Fig. I, 2. Linke und rechte Schale des $\sigma^{7} \cdot 22 \times$.

Fig. 3, 4. Linke und rechte Schale des $9.22 \times$.

Fig. 5, 6. Innenast der 2. Antn. des $0^{7}, 5$ nur das terminale Glied gezeichnet. I 54 und $90 \times$.

Fig. 7. Putsfuss, das terminale Stück soweit es mit Borsten besetzt ist gezeichnet, die Borsten meist gekürzt . $154 \times$.

Fig. 8. Oberlippe des $9.90 \times$.

Fig. 9. Ende des Mandibulartasters des $0^{7}$. $154 \times$.

Fig. IO-I3. Codonocera goniacantha. S. 28 ,

Fig. IO, Ir. Linke und rechte Schale des $\sigma^{7} \cdot 22 \times$.

Fig. I2, I3. Linke und rechte Schale des .. $22 \times$.

Fig. 14-20. Codonocera pusilla. S. 27.

Fig. I4, I5. Linke und rechte Schale des $0^{7} .22 \times$.

Fig. 16, 17. Linke und rechte Schale des $9.22 \times$.

Fig. I8. Greifborste der I. Antn. des $\sigma^{\top} .270 \times$.

Fig. I9. Die beiden basalen Glieder der 1. Antn. des $9.154 \times$.

Fig. 20. Innenast der 2. Antn. des $07.154 \times$.

Fig. 2I, 22. Codonocera goniacantha. Innenast der 2. Antn. des $\sigma^{7} \cdot 154 \times$. 


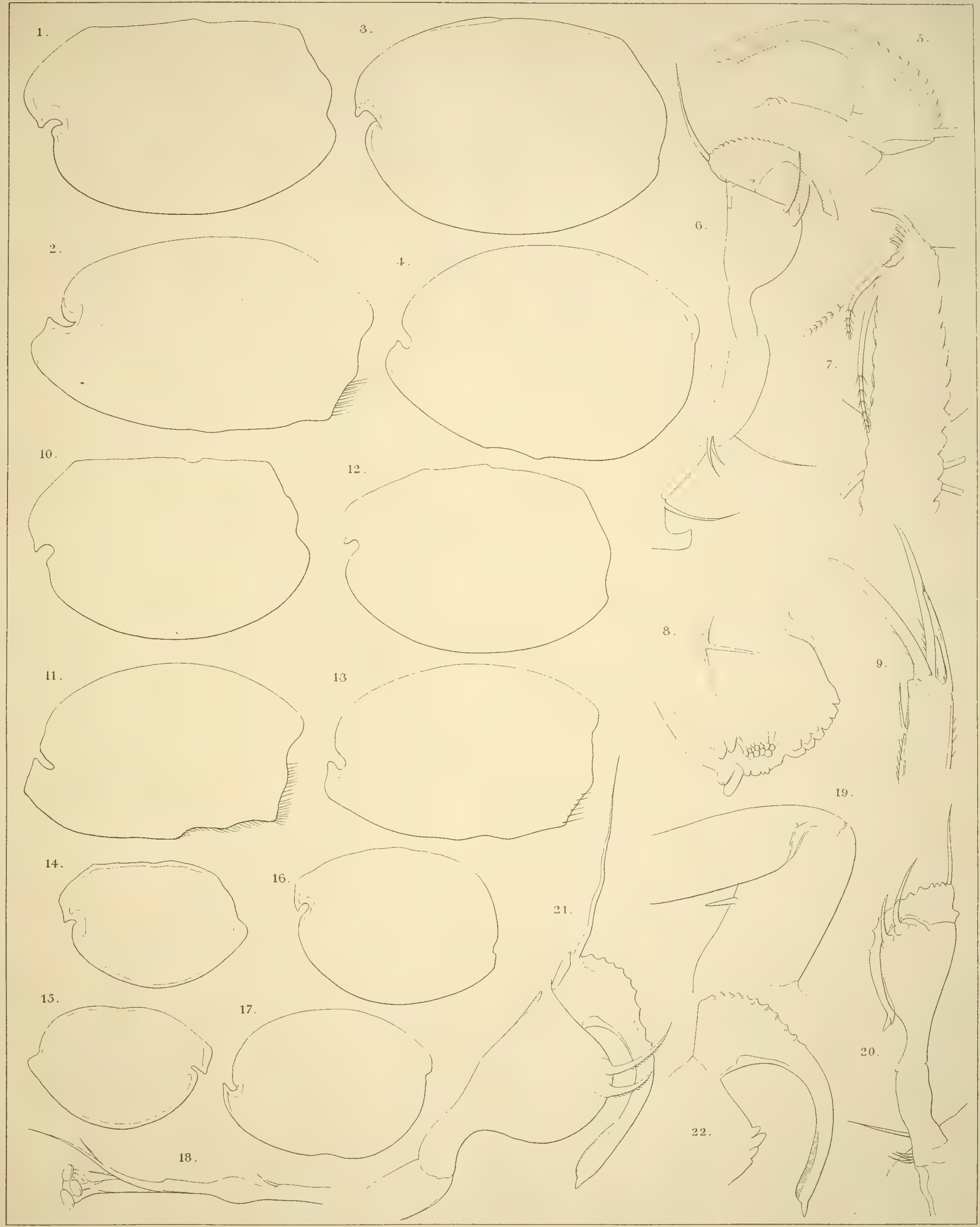






\section{TAFEL VIII.}

Fig. I-6. Codonocera cruenta. S. 25.

Fig. I. Linke Schale des $0^{7} \cdot 43 \times$.

Fig. 2, 3. Linke und rechte Schale des $87.22 \times$.

Fig: 4, 5. Linke und rechte Schale des $q .22 \times$.

Fig. 6. Furca, beide Äste gezeichnet. $90 \times$.

Fig. 7-9. Codonocera weberi. S. 24.

Fig. 7. Innenast und Spitze des Stammes der 2. Antn. des $0^{7} \cdot 90 \times$.

Fig. 8. Schalenskulptur. $154 \times$.

Fig. 9. Linke Schale des . $38 \times$.

Fig. IO. Codonocera cruenta $\sigma^{7}$, 2. thoracale Gliedmaasse. I $54 \times$. 

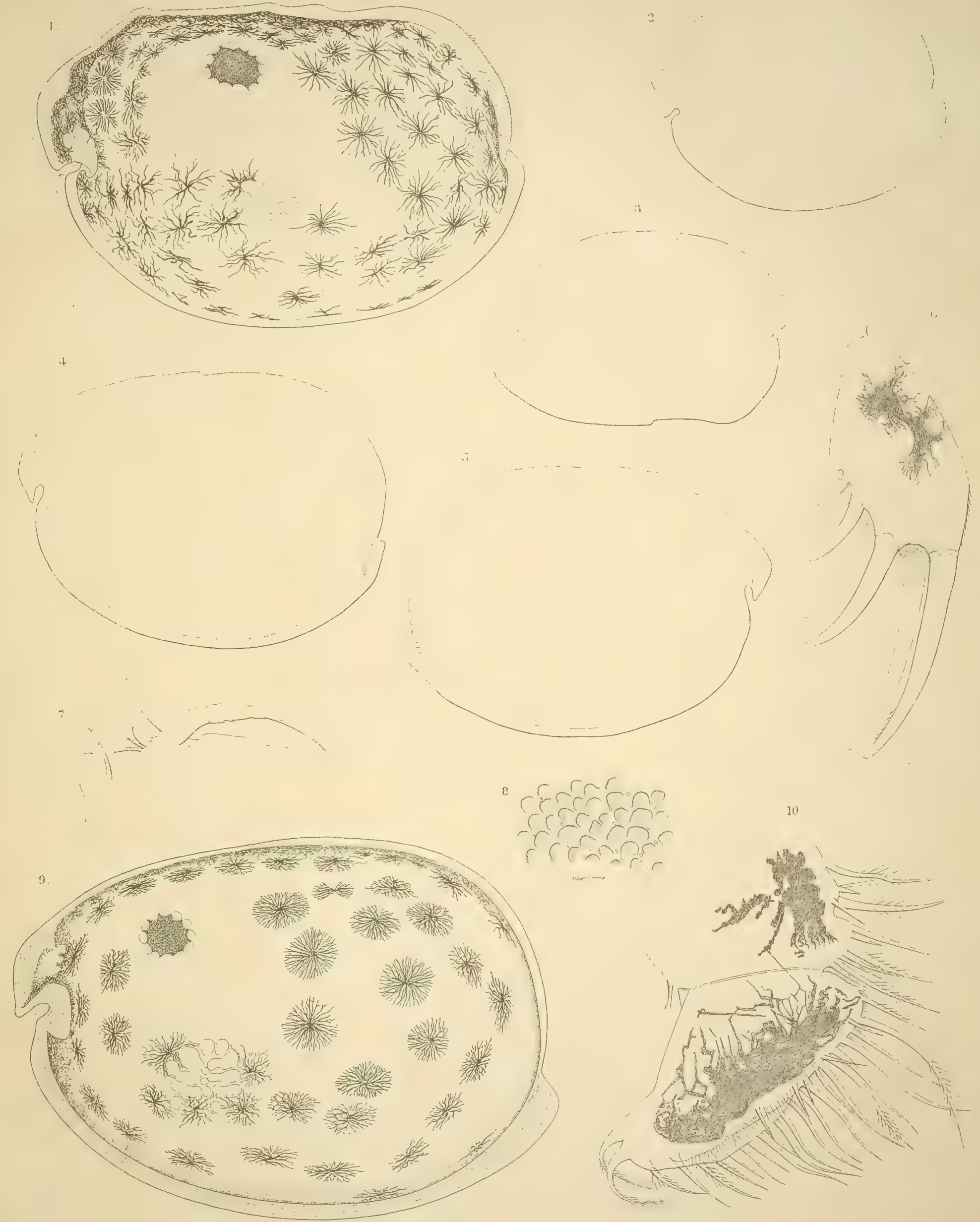



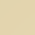




\section{TAFEL IX.}

Fig. I-6. Codonocera weberi. S. 24 .

Fig. I, 2. Linke und rechte Schale des . $.22 \times$.

Fig. 3, 4. Linke und rechte Schale des $8.22 \times$.

Fig. 5. Spitze der Greifborste der I. Antn. des $\sigma^{7} .270 \times$.

Fig. 6. Innenast der 2. Antn. des $0^{7}$. I I $8 \times$.

Fig. 7, 8. Codonocera cruenta. Innenast der 2 Antn. des $\sigma^{7}$. II $8 \times$.

Fig. 9-I4. Codonocera polygonia. S. 26.

Fig. 9, IO. Linke und rechte Schale des $0^{7} .22 \times$.

Fig. II, I2. Linke und rechte Schale des $0.22 \times$.

Fig. 13. Greifborste der I Antn. des $0^{7} .270 \%$

Fig. I4. Innenast der 2 Antn. tes $\sigma^{7} \cdot 154 \delta^{7}$.

Fig. I5-19. Codonocera penicillum. S. 25.

Fig. I5, I6. Linke und rechte Schale des $0^{7} \cdot 22 \times$.

Fig. I7, 18. Innenast der 2. Antn. des 0 . $154 x$.

Fig, 19. Vorderrand des basalen Gliedes der I. Antn. des $\sigma^{7}$. I54 X. 
Siboga-Expeditie. XXX. G. W. Mulder, Ostracoda.

I.1:

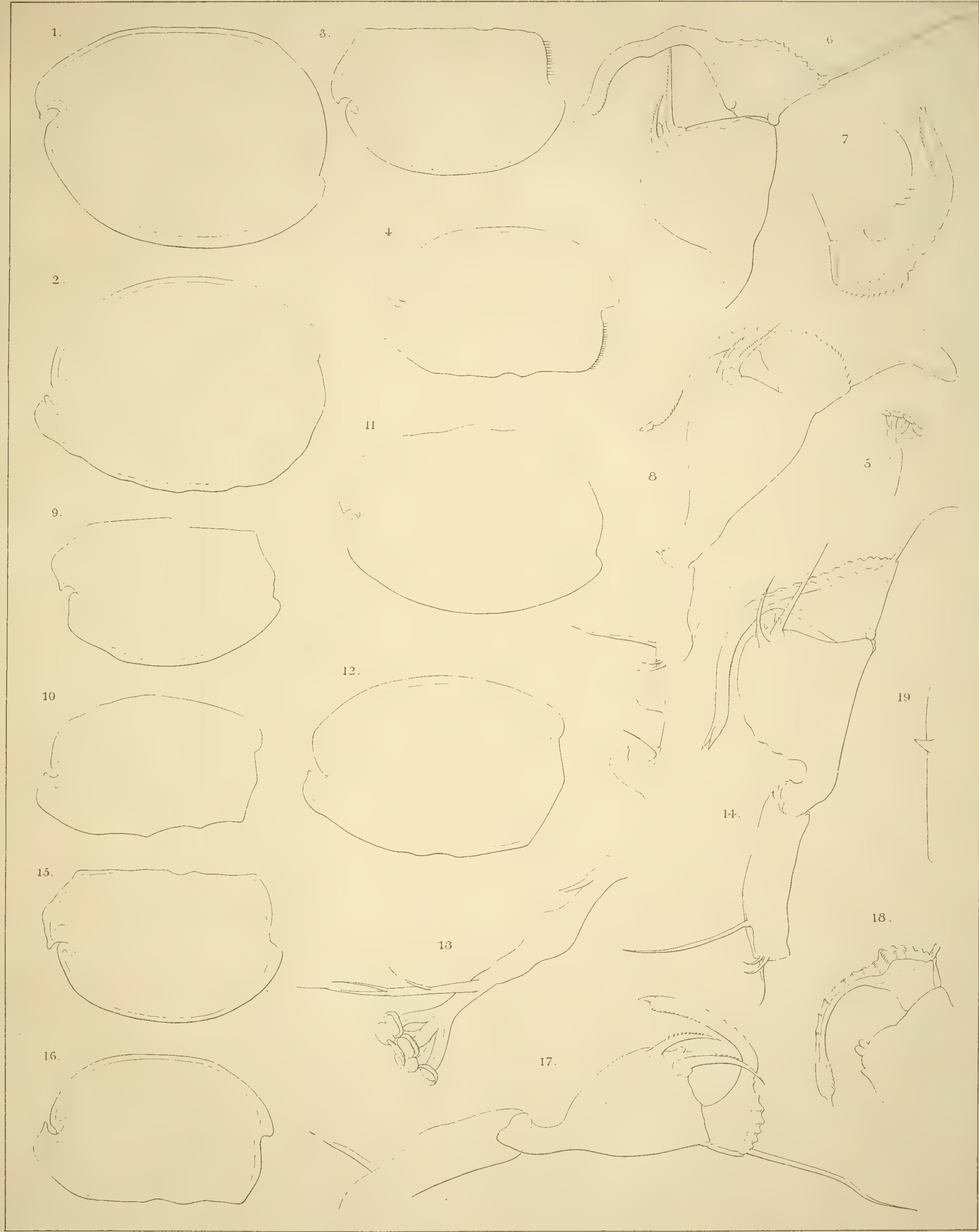

Muller, gez

P. W. M. Trap, impr. 



\section{CONDITIONS GÉNÉRALES DE VENTE.}

I. L'ouvrage du „Siboga” se composera d’une série de monographies.

$2^{\circ}$. Ces monographies paraîtront au fur et à mesure qu'elles seront prêtes.

$3^{\circ}$. Le prix de chaque monographie sera différent, mais nous avons adopté comme base générale du prix de vente: pour une feuille d'impression sans fig. flor. 0.15 ; pour une feuille avec fig. flor. 0.20 à 0.25 ; pour une planche noire flor. 0.25 ; pour une planche coloriée flor. 0.40 ; pour une photogravure flor. 0.60 .

$4^{\circ}$. Il y aura deux modes de souscription:

a. La souscription à l'ouvrage complet.

b. La souscription à des monographies séparées en nombre restreint.

Dans ce dernier cas, le prix des monographies sera majoré de $25 \%$.

$5^{\circ}$. L'ouvrage sera réuni en volumes avec titres et index. Les souscripteurs à l'ouvrage complet recevront ces titres et index, au fur et à mesure que chaque volume sera complet. 


\section{Déjà paru:}

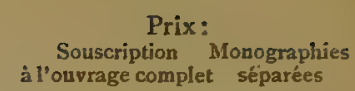

Ie Livr. (Monogr. XLIV) C. Ph. Sluiter. Die Holothurien der Siboga-Expedition. Mit ro Tafeln. $f$ 6. $-f 7.50$

2 e Livr. (Monogr. LX) E. S. Barton: The genus Halimeda. With 4 plates. . . . . . . ” 1.80 » 2.40

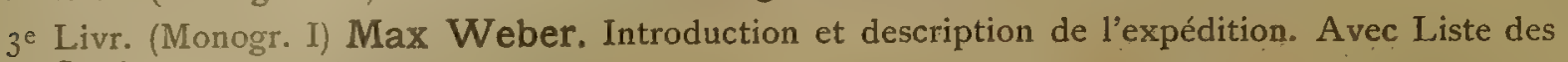

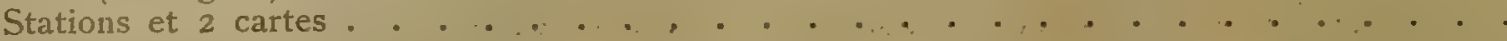

$4^{e}$ Livi: (Mínogr. II) G. F. Tydeman. Description of the ship and appliances used for scientific exploration. With 3 plates and illustrations.

$5^{e}$ Livr. (Monogr. XLVII) H. F. Nierstrasz. The Solenogastres of the Siboga-Exp. With 6 plates.

Ge Livr. (Monogr. XIII) J. Versluys. Die Gorgoniden der Siboga-Expedition.

I. Die Chrysogorgiidae. Mit I70 Figuren im Text. . . . . . . . . .

$7^{\mathrm{e}}$ Livr. (Monogr. XVIa) A. Alcock. Report on the Deep-Sea Madreporaria of the SibogaExpedition. With 5 plates. $\cdot \cdot \cdot \cdot \cdot \cdot \cdot \cdot \cdot \cdot \cdot \cdot \cdot \cdot \cdot \cdot \cdot \cdot \cdot$

Se Livr. (Monogr. XXV) C. Ph. Sluiter. Die Sipunculiden und Echiuriden der Siboga-Exp.

Mit 4 Tafeln und 3 Figuren im Text. . . . . . . . . . . . . . . . . . . .

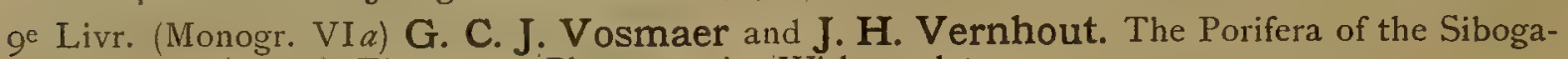

Expedition. I. The genus Placospongia. With 5 plates. . . . . . . . . . . .

roe Livr. (Monogr. XI) Otto Maas. Die Scyphomedusen der Siboga-Expedition. Mit I 2 Tafeln.

I I $^{\mathrm{e}}$ Livr. (Monogr. XII) Fanny Moser. Die Ctenophoren der Siboga-Expedition. Mit 4 Tafeln.

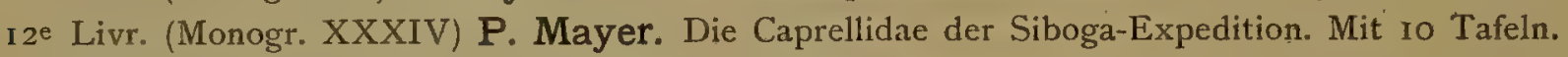

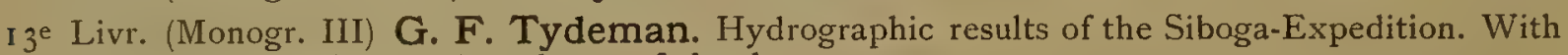
24 charts and plans and 3 charts of depths .. . . . . . . . . . . . . . .

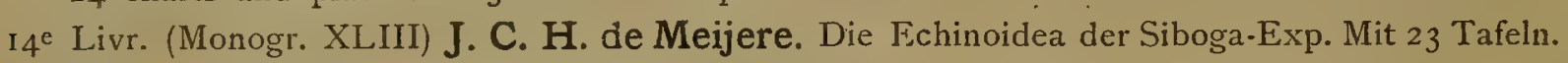

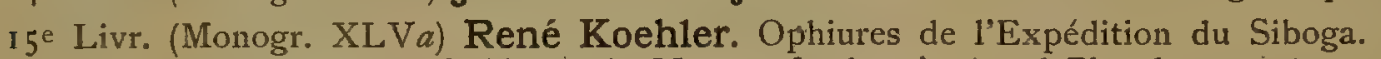

Ie Partie. Ophiures de Mer profonde: Avec 36 Planches. … . . . . . „16.50 , 20.50

I6e Livr. (Monogr. LII) J. J. Tesch. The Thecosomata and Gymrosomata of the SibogaExpedition. With 6 plates.

I 7 e Livr. (Monogr. LVI a) C. Ph. Sluiter. Die Tunicaten der Siboga-Expedition.

I. Abteilung. Die socialen und holosomen Ascidien. Mit I5 Tafeln .

I Se Livr. (Monogr. LXI) A. Weber-van Bosse and M. Foslie. The Corallinaceae of the Siboga-

Expedition. With 16 plates and 34 textfigures . . . . . . . . . . . . . . . .

19e Livr. (Monogr. VIII) Sydney J. Hickson and Helen M. England. The Stylasterina of the Siboga Expedition. With 3 plates. . . . . . . . . . . . . . . . . . 20 Livr. (Monogr. XLVIII) H. F. Nierstrasz. Die Chitonen der Siboga-Exp. Mit 8 Tafeln. $2 r^{\mathrm{e}}$ Livr. (Monogr. XLVb) René Koehler. Ophiures de l'Expédition du Siboga.

$2^{\mathrm{e}}$ Partie. Ophiures littorales. Avec $\mathrm{r} 8$ Planches. . . . . . . . . . .

$22^{e}$ Livr. (Monogr. XXVIbis) Sidney F. Harmer. The Pterobranchia of the Siboga-Expedition, with an account of other species. With 14 plates and 2 text-figures.

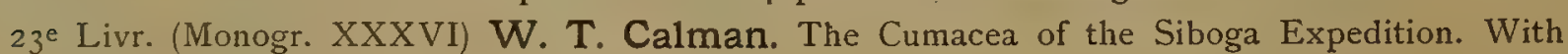
2 plates and 4 text-figures

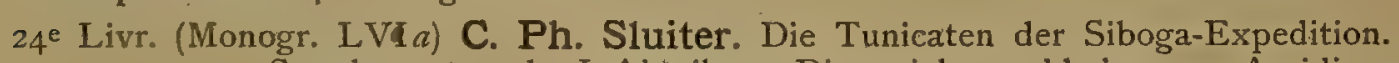

Supplement zu der I. Abteilung. Die socialen und holosomen Ascidien. Mit I Tafel.

$25^{e}$ Livr. (Monogr. L) Rud. Bergh. Die Opisthobranchiata der Siboga-Exped. Mit 20 Tafeln.

26e Livr. (Monogr. X) Otto Maas. Die Craspedoten Medusein der Siboga-Exp. Mit i4 Tafeln.

$27^{e}$ Livr. (Monogr. XIII a) J. Versluys. Die Gorgoniden der Siboga-Expedition.

II. Die Primnoidae. Mit IO Tafeln, 178 Figuren im Text und einer Karte. .

28e Livr. (Monogr. XXI) G. Herbert Fowler. The Chaetognatha of the Siboga Expedition.

With 3 plates and 6 charts .

$2 g^{e}$ Livr. (Monogr. LI) J. J. Tesch. Die Heteropoden der Siboga-Expedition. Mit i4 Tafeln.

30e Livr. (Monogr. XXX) G. W. Müller. Die Ostracoden der Siboga-Exped. Mit 9 Tafeln.

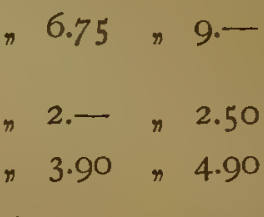

n3.- $\rightarrow 3.75$

^ $4.60 \quad 75.75$

\# $3 .-\quad 3.75$

$\pi 2.40 \pi 3 .-$

"7.50 79.50

" $2.80 \% 3.50$

n $7.80,9.75$

" 9.- 711.25

15.

" 3.75 " 4.70

6.75 , 9.-

II $2.50 \quad I 5.50$

n $1.50,1.90$

, $5 .-, 6.25$

. $10.25, \mathrm{I} 2.75$

"6.75, $9 .-$

" $1.80 \cap 2.40$

$,-75,71 .-$

nII.25 \# 14.10

त 9.25 ॠ 12.50

, $12.50 \quad-16.75$

" $4.20 \gg 5.25$

" $6.75 \gg 9 .-$

"3.50 $\# 4.40$ 



